Aus der Abteilung Kardiologie und Pneumologie

(Prof. Dr. med. G. Hasenfuß)

im Zentrum Innere Medizin

der Medizinischen Fakultät der Universität Göttingen

\title{
Wertigkeit von NT-proBNP, Surfactant Protein-B und Surfactant Protein-D als Marker zur Differentialdiagnose bei Patienten mit akuter Dyspnoe
}

\author{
INAUGURAL - DISSERTATION \\ zur Erlangung des Doktorgrades \\ der Medizinischen Fakultät \\ der Georg-August-Universität zu Göttingen
}

vorgelegt von

Jens Schaumberg

aus

Halberstadt

Göttingen 2010 
Dekan: Prof. Dr. med. C. Frömmel

I. Berichterstatter: Prof. Dr. med. B. Pieske

II. Berichterstatter/in: Prof. Dr. N. von Ahsen

III. Berichterstatter/in: Prof. Dr. P. Virsik-Köpp

Tag der mündlichen Prüfung: 17.01.2011 


\section{$\underline{\text { Inhaltsverzeichnis }}$}

1. Einleitung

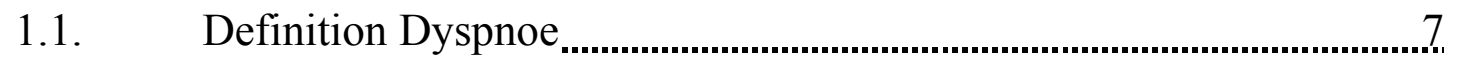

1.2. Pathophysiologie der Dyspnoe

1.3. Definition, Ursache und Verlauf der Herzinsuffizienz .............................

1.4. Diagnostik bei Patienten mit akuter Dyspnoe ............................................

1.5. Synthese, Struktur und Sekretion der natriuretischen

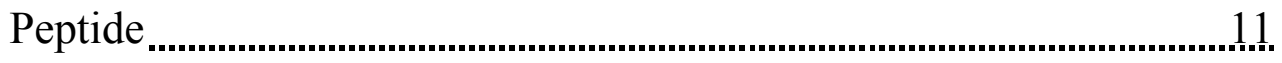

1.6. Funktion und Eigenschaften der natriuretischen Peptide .........................

1.7. Funktion, Eigenschaften und Sekretion der Surfactant

Proteine

1.8. Hypothese und Zielsetzung..................................................................

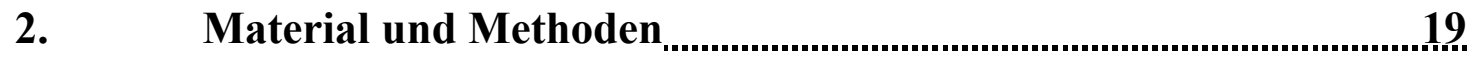

2.1. Patientenrekrutierung und Patientenzahl ..............................................19.

2.1.1. Einschlusskriterien ........................................................................19.

2.1.2. Ausschlusskriterien .....................................................................19.

2.1.3. Studienablauf und Studiendesign .......................................................19.

2.1.4. Parameter zur differentialdiagnostischen Beurteilung der akuten Dyspnoe

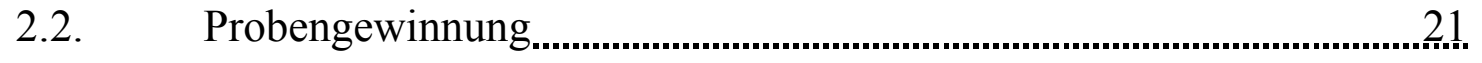

2.3. Messung von NT-proBNP .....................................................................

2.3.1. Messung von SP-B und SP-D ............................................................ 22

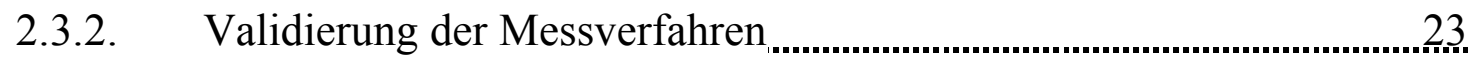

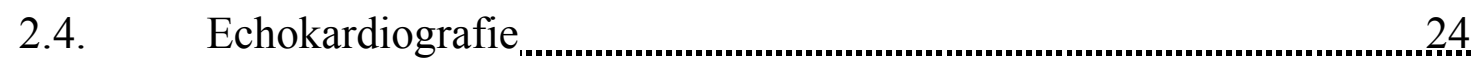

2.5. Statistische Datenerhebung und Verarbeitung ........................................

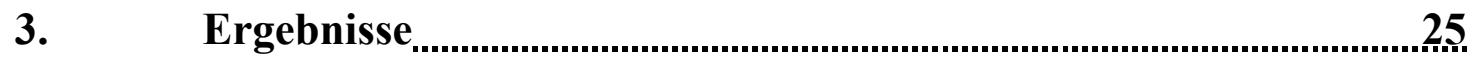

3.1. Subgruppen der akuten Dypnoe

3.2. Patienten mit kardialer Ursache der akuten Dyspnoe ...............................

3.3. Patienten mit kardiopulmonaler Ursache der akuten Dyspnoe,............28

3.4. Patienten mit pulmonaler Ursache der akuten Dyspnoe .........................29. 
3.5. Patienten mit extrakardiopulmonaler Ursache der akuten Dyspnoe

3.6. Klassifikation der Ursachen der akuten Dyspnoe .................................. 30

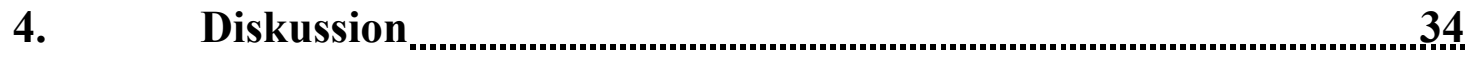

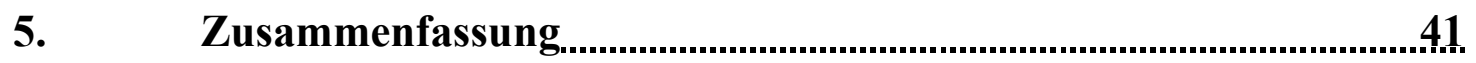

6. Literaturverzeichnis ................................................................. 


\section{Abkürzungsverzeichnis}

ACE

ANP

ARDS

AUC

BAL

BMI

BNP

cGMP

CNP

COPD

DPPC

EF

HWZ

n.a.

KHK

KÖF

LDA

LVD

NEPs

NP

NPR

NT-proANP

NT-proBNP

NYHA I-IV

Pmv

RAAS

S.D.

SP-A
Angiotensin konvertierendes Enzym

atriales natriuretisches Peptid

Atemnotsyndrom des Erwachsenen (Acute Respiratory Distress Syndrome )

Fläche unter der Kurve

bronchoalveoläre Lavage

Body Mass Index

B-Typ-natriuretisches Peptid

zyklisches Guanosinmonophosphat

C-Typ-natriuretisches Peptid

chronisch obstruktive Lungenerkrankung

Dipalmitoylphosphatidylcholine

linksventrikuläre Ejektionsfraktion

Halbwertzeit

nicht aufgeführt

koronare Herzkrankheit

Körperoberfläche

lineare Diskriminanzanalyse

linksventrikuläre Dysfunktion

neutrale Endopeptidase

natriuretische Peptide

natriuretischer Peptidrezeptor

N-terminales Pro-Atriales Natriuretisches Peptid

N-terminales Pro-Brain Natriuretisches Peptid

Stadien der Herzinsuffizienz nach Klassifikation der New York

Heart Assoziation

mikrovaskulärer Druck

Renin-Angiotensin-Aldosteron-System

Standardabweichung

Surfactant Protein-A 
Surfactant Protein-B

SP-C

Surfactant Protein-C

SP-D

Surfactant Protein-D 


\section{Einleitung}

\subsection{Definition Dyspnoe:}

Die dyspnoische Atmung äußert sich subjektiv in dem Gefühl von Atemnot, Lufthunger oder Beklemmung. Meakins gab als praktische Wegleitung die Definition: „Von Dyspnoe kann gesprochen werden, wenn ein Kranker die Notwendigkeit zu gesteigerter Atemtätigkeit subjektiv empfindet" (Siegenthaler 2000,S 448, American Thoracic Society 1999). Man unterscheidet dabei die Ruhe - und Belastungsdyspnoe sowie eine akute und eine chronische Form der Dyspnoe (Classen et al. 1998).

\subsection{Pathophysiologie der Dyspnoe:}

Pathophysiologisch entspricht die Dyspnoe einem Missverhältnis zwischen notwendigem Gasaustausch und der dazu erforderlichen Leistung der Atemmuskulatur. Sie kann durch die in Ruhe oder bei Arbeit gesteigerte Atemarbeit objektiviert werden. Dyspnoe wird auch empfunden, falls eine normale Arbeit von einer insuffizienten Atemmuskulatur geleistet werden muss. Da definitionsgemäß die Dyspnoe eine subjektiv empfundene Wahrnehmung ist, kann sie der Untersucher nicht feststellen. Nur die Charakteristik einer veränderten Atmung, wie Tachypnoe, Orthopnoe, periodische Atmung usw., welche oft mit einer Dyspnoe einhergehen, ist erkennbar (Classen et al. 1998).

Zur Erfassung der Dyspnoe werden folgende Grade (Kategorien) nach der New York Heart Association unterschieden (NYHA-Klassifikation):

- Kategorie I: Keine Dyspnoe.

- Kategorie II: Dyspnoe bei schwerer Belastung (Treppensteigen).

- Kategorie III: Dyspnoe bei leichter Belastung (Gehen auf ebener Erde). 
- Kategorie IV: Ruhedyspnoe (Little et al. 1994).

Als Ursache einer Dyspnoe kommen folgende pathophysiologische Mechanismen und Krankheiten in Frage:

extrapulmonal: Hypoxie, Hypoxämie, Anämie, metabolische Azidose, Störung im Bereich des Atemzentrums, Fieber, Hyperthyreose, Gravidität, Adipositas, emotionale Faktoren und Pharmaka, neuronale Störungen;

pulmonal: $\quad$ erhöhte Atemwegswiderstände (Trachealstenose, Asthma, Bronchitis, Emphysem), verminderte Gasaustauschfläche und Lungendehnbarkeit (Lungenfibrose), Totraumhyperventilation (Lungenembolie), Thoraxdeformitäten (Kyphoskoliose) und Zwerchfelllähmung;

Erscheinungsformen der pulmonalen Dyspnoe:

Restriktion:

parenchymale: Atelektasen, Pneumonien, Granulomatosen, diffuse Lungenfibrose, Pneumokoniosen, Resektionen extraparenchymale: Ergüsse, Pneumothorax, Kyphoskoliose, Thorakoplastik, Pleuraschwarte

\section{Obstruktion:}

In- und exspiratorische Stenosen im Bereich der Bronchien und Bronchiolen (Asthma bronchiale, chron. Bronchitis, Bronchiolitis, Lungenemphysem, Lungenstauung) 

zeitvolumen bei normalem enddiastolischen Ventrikeldruck zu fördern (Herzinsuffizienz).

\subsection{Definition, Ursache und Verlauf der Herzinsuffizienz}

„, Bei der Herzinsuffizienz ist das Herz nicht mehr in der Lage, die Gewebe mit genügend Blut und damit genügend Sauerstoff zu versorgen, um den Gewebestoffwechsel in Ruhe oder unter Belastung sicherzustellen “(Hoppe et al. S. 488-489:2005).

Das klinische Syndrom der Herzinsuffizienz betrifft jedoch als Folge einer initialen primären Myokardschädigung den gesamten Organismus. Dabei unterscheidet man ein Vorwärts- („forward failure“) und ein Rückwärtsversagen (,backward failure“). Dem Vorwärtsversagen liegt eine verminderte Pumpfunktion des Herzmuskels zugrunde. Im Rückwärtsversagen können eine vermehrte Steifigkeit sowie eine verminderte Füllung beobachtet werden (Erdmann 2003). Es resultieren myokardiale Schwäche und gesteigerte Ermüdbarkeit. Im Verlauf kommt es frühzeitig zur Aktivierung neuroendokriner Gegenregulationsmechanismen auf lokaler und später auf systemischer Ebene. Diese haben kurzfristig eine Steigerung des Herzminutenvolumens und die sichere Versorgung lebenswichtiger Organe zum Ziel, tragen jedoch bei dauerhafter Aktivierung erheblich zur Progression der Herzinsuffizienz bei.

$\mathrm{Zu}$ diesen Gegenregulationsmechanismen gehören die Aktivierung des sympathischen Nervensystems, die Stimulation des Renin-Angiotensin-Aldosteron Systems und die gesteigerte Freisetzung von Vasopressin. Zusätzlich haben weitere Faktoren, wie die Aktivierung proinflammatorischer Zytokine oder freie Sauerstoffradikale, schädigende Einflüsse auf das Myokard. Unter anderem aufgrund dieser Gegenregulation entwickelt sich dann in der Folge das Vollbild der chronischen Herzinsuffizienz (Erdmann 2003).

Für die Diagnose einer Herzinsuffizienz etablierten die Autoren der FraminghamStudie Haupt- und Nebenkriterien. Die definitive Diagnose einer Herzinsuffizienz 
kann gestellt werden, wenn mindestens 2 Hauptkriterien oder 1 Hauptkriterium und 2 Nebenkriterien (siehe Tabelle 1) vorliegen. Dabei sollte ein Nebenkriterium nicht durch eine andere pathophysiologische Konstellation zu erklären sein (McKee et al. 1971).

\begin{tabular}{|c|c|}
\hline \multicolumn{2}{|c|}{ Hauptkriterien } \\
\hline paroxysmale nächtliche Dyspnoe & Orthopnoe \\
\hline Halsvenenstauung & Kardiomegalie \\
\hline feuchte Rasselgeräusche & akutes Lungenödem \\
\hline $\mathrm{ZVD} \geq 16 \mathrm{~cm} \mathrm{H}_{2} \mathrm{O}$ & mittlere Zirkulationszeit $\geq 25 \mathrm{~s}$ \\
\hline hepatojugulärer Reflux & $\begin{array}{l}\text { Gewichtsverlust } \geq 4,5 \mathrm{~kg} \text { in } 5 \mathrm{~d} \\
\text { Behandlung }\end{array}$ \\
\hline 3. Herzton mit Galopprhythmus & \\
\hline \multicolumn{2}{|c|}{ Nebenkriterien } \\
\hline Knöchelödeme & Pleuraergüsse \\
\hline nächtlicher Husten & Vitalkapazität $\leq 1 / 3$ Max. \\
\hline Belastungsdyspnoe & Tachykardie $\geq 120 / \mathrm{min}$ \\
\hline Hepatomegalie & $\begin{array}{l}\text { Gewichtsverlust } \geq 4,5 \mathrm{~kg} \text { in } 5 \mathrm{~d} \\
\text { Behandlung }\end{array}$ \\
\hline
\end{tabular}

Tabelle 1: Haupt- und Nebenkriterien für die Diagnose einer Herzinsuffizienz nach den Kriterien der Framingham-Studie (McKee et al. 1971).

Ursache der Herzinsuffizienz in den Industrieländern ist meistens eine KHK (54-70\%), die bei $35-52 \%$ dieser Patienten von einer arteriellen Hypertonie begleitet ist. Eine isolierte arterielle Hypertonie als alleinige Ursache der Herzinsuffizienz wird bei 9-20\% der Patienten angenommen (Hoppe et al. 2005). Die chronische Herzinsuffizienz hat bei Männern eine höhere Prävalenz als bei Frauen, wobei sich Prävalenz und Inzidenz in den letzten zehn Jahren verdoppelt haben. Die Mehrzahl der Patienten mit chronischer Herzinsuffizienz oder linksventrikulärer Dysfunktion sind jedoch unentdeckt und nicht ausreichend behandelt. Der natürliche Krankheitsverlauf von Patienten mit systolischer Herzinsuffizienz wird durch den Grad der Pumpfunktionsstörung, die Symptomatik, die Belastbarkeit und Begleiterkrankungen beeinflusst (Hoppe et al. 2005). Die 5-Jahres-Überlebensrate liegt bei ungefähr 50\%, wobei die jährliche Sterberate vom Grad der Erkrankung abhängt. So liegt die 5-Jahres-Überlebensrate bei asympto- 
matischen Patienten bei 5\% und bei Patienten im Stadium NYHA IV bei $30-80 \%$. Bei milder Herzinsuffizienz (NYHA II) liegt die jährliche Sterberate bei 10\% und bei einer Herzinsuffizienz Stadium NYHA III bei 20\%. Von daher ist eine frühe Identifikation der Herzinsuffizienz sehr wichtig. Dabei spielt die rechtzeitige medikamentöse Therapie zur Verbesserung der Symptome, Verzögerung der Krankheitsprogression sowie die Senkung der Morbidität und Mortalität eine entscheidende Rolle. Auch der Nachweis einer linksventrikulären Dysfunktion ist hierbei essentiell (Mair et al. 2001).

\subsection{Diagnostik bei Patienten mit akuter Dyspnoe}

Allein in Europa werden pro Jahr über 1 Mio. Patienten wegen akuter Dyspnoe hospitalisiert. Bei mehr als der Hälfte dieser Patienten ist eine Herzinsuffizienz Ursache der Atemnot (Müller et al. 2003). Eine gründliche Anamnese, körperliche Untersuchung, EKG, Thorax-Röntgenbild und die Sauerstoffsättigung stehen für eine schnelle Differentialdiagnose zur Verfügung. Mit diesen Methoden ist es bei der Mehrzahl der Patienten möglich, eine Herzinsuffizienz von anderen in Frage kommenden Erkrankungen (z.B. Exazerbation einer chronisch-obstruktiven Lungenerkrankung, Lungenembolie, Pneumonie, Pneumothorax, Hyperventilation) abzugrenzen. Dagegen kann es vor allem bei adipösen Patienten, alten Patienten und Patienten mit Begleiterkrankungen (z.B. koronare Herzkrankheit und COPD) schwierig sein, die Ursache der akuten Dyspnoe auf der Notfallstation herauszufinden (Müller et al. 2003). Hinzukommend bilden z.B. das Auftreten von Bronchospasmen bei älteren Patienten mit chronischer Herzinsuffizienz (Asthma cardiale) sowie die schwer zu diagnostizierende diastolische Herzinsuffizienz Faktoren, welche die Diagnose der Ursache der akuten Dyspnoe meist erschweren können (Cabanes et al. 2001, Müller et al. 2003).

\subsection{Synthese, Struktur und Sekretion der natriuretischen Peptide}

Als erstes natriuretisches Peptid wurde 1981 das Atriale natriuretische Peptid oder Atype natriuretic peptide (ANP) beschrieben. Man fand eine Substanz in den Vorhöfen von Ratten, welche eine natriuretische und vasodilatierende Wirkung aufwies. Die Struktur dieser Substanz wurde 1984 identifiziert. 1991 konnte erstmalig das B-type 
natriuretic peptide aus dem Gehirn von Schweinen isoliert werden. Später stellte sich jedoch heraus, dass die Herzkammern wesentlicher Bildungsort dieses Peptids sind und nicht, wie vorher angenommen, das Gehirn. Als drittes Mitglied dieser Peptidfamilie konnte man das C-type natriuretic peptide isolieren, welches ein parakrines Hormon mit hoher Konzentration im Gefäßendothel ist (Mair et al 2001).

Den Vorstufen der natriuretischen Peptide ist ein charakteristischer Aufbau aus einer 17-Aminosäuren-Ring-Struktur mit einer Disulfidbrücke zwischen zwei Cysteinresten gemein. Diese Ringstruktur zeigt bei den verschiedenen natriuretischen Peptiden groBe Gemeinsamkeiten, dabei sind 11 der 17 Aminosäuren in jedem NP gleich. Dieser homologe Aufbau ist für die Rezeptorbindung und für die biologische Aktivität essentiell. ANP und CNP zeigen weiterhin große Übereinstimmungen bei allen Spezies, wohingegen BNP sehr spezifisch für die jeweilige Spezies ist (Mair et al. 2001).

Der Ursprung von ANP und BNP ist größtenteils kardial. Sie sind zirkulierende Hormone mit natriuretischer, vasodilatativer, renininhibierender, antimitotischer und lusitropischer Wirkung. Somit stellen sie Schlüsselregulatoren in der Salz- und Wasserhomöostase und in der Regulation des Blutdrucks dar. Unter physiologischen Verhältnissen werden ANP und BNP aus den kardialen Vorhöfen freigesetzt. Bei linksventrikulärer Dysfunktion, ventrikulärer Hypertrophie und anderen pathologischen Veränderungen mit chronischer Druck- oder Volumenbelastung kommt es bei den ventrikulären Myozyten unter einer Modifikation des Phänotyps zu einer „Wiederexpression" einiger fetaler Gene, darunter ANP und BNP. Somit werden unter diesen Umständen die Herzkammern zur wichtigsten Quelle der natriuretischen Peptide, vor allem jedoch des BNP. Das Plasmakonzentrationsverhältnis von ANP : BNP ändert sich folglich zugunsten des BNPs. Die menschlichen Gene für das ANP und BNP sind auf dem Chromosomen 1 lokalisiert. Die Transkription der Gene wird von ZinkFinger-Transkriptionsfaktoren (GATA 4 und GATA 6) reguliert. Die Expression von BNP erfolgt im Vorhof und im Ventrikel des Herzens, wohingegen die ANPExpression im Ventrikel in den ersten postnatalen Wochen schnell herunterreguliert wird. Beim Erwachsenen ist daher die ANP-Sekretion meist vorhofspezifisch (Mair et al. 2001). 
BNP wird hauptsächlich auf der Ebene der Proteinbiosynthese direkt synthetisiert, wobei geringe Mengen auch in den Granula des Vorhofs und der Kammern gespeichert werden. Unter pathophysiologischen Verhältnissen wird, wie oben erwähnt, das BNP hauptsächlich aus den Ventrikeln freigesetzt (Mair et al. 2001). Dabei spielt die linksventrikuläre Dehnung bzw. die Wandspannung als Reiz eine wesentliche Rolle. BNP wird dabei in NT-proBNP 1-76 und ein C-terminales Peptid mit 32 Aminosäuren (BNP) gespalten. ProBNP ist dabei das Substrat für die Serinprotease CORIN und möglicherweise findet die Spaltung des BNP in den Kardiomyozyten statt. Die Rolle des dabei entstehenden NT-proBNPs ist zum jetzigen Zeitpunkt noch völlig unklar (Mair et al. 2001).

\subsection{Funktion und Eigenschaften der natriuretischen Peptide}

ANP und BNP stellen natürliche Antagonisten des Renin-Angiotensin-AldosteronSystems (RAAS) und des zentralen sowie peripheren sympathischen Nervensystems dar. Alle drei natriuretischen Peptide werden auch in Strukturen des zentralen Nervensystems gebildet und verstärken über zentrale Wirkmechanismen deren periphere Wirkung: im Gehirn senken die NPs den Sympathikotonus, im Hypothalamus die Sekretion von Arginin-Vasopressin und Kortikotropin. In Bereichen um den dritten Ventrikel supprimieren sie die Natriumhomöostase und das Verlangen, Wasser zu trinken. Die Freisetzung aller natriuretischen Peptide wird dabei durch andere Neurohormone wie Endothelin, Arginin-Vasopressin und Phenylepinephrine verstärkt (Mair et al. 2001).

Die natriuretischen Peptide sind bei allen Zuständen der Volumenbelastung mit gesteigerter Vorhof- und Kammerwandspannung, wie z.B. Herzinsuffizienz, Nierenversagen und Leberzirrhose mit Aszites, erhöht. Die NPs senken ferner den systemischen und pulmonalen Blutdruck, den venösen Rückfluss und reduzieren den enddiastolischen Druck in den Vorhöfen und den Herzkammern. Dies hat eine Steigerung des Herzzeitvolumens und eine bessere systolische und diastolische Funktion zur Folge. Weiterhin hemmen die natriuretischen Peptide das parasympathische Nervensystem und damit eine Vasokonstriktion. Sie steigern ebenfalls den koronaren und renalen Blutfluss, die glomeruläre Filtrationsrate und die Urinausscheidung. Auch wird die Freisetzung von 
Renin und Aldosteron inhibiert, wobei ANP zusätzlich auch die Aldosteronbiosynthese hemmt. Die natriuretischen Peptide unterstützen die antimitotische und antiproliferative Aktivität im kardiovaskulären System und modulieren das Zellwachstum sowie die Proliferation und Kardiomyozytenhypetrophie (Mair et al. 2001, Ellis et al. 1998).

Natriuretische Peptide sind Liganden für drei unterschiedliche natriuretische PeptidRezeptoren. Diese werden als NPR-A, NPR-B und NPR-C bezeichnet. Die Typ-Aund -B-Rezeptoren sind Transmembranproteine und zählen zur Familie der Guanylatcyclase-Rezeptoren mit einer extrazellulären Hormon-Bindungs-Domäne, einer transmembranen Domäne, welche die extra- und intrazellulären Domänen verbindet, sowie einer intrazellulären „,kinase-like-domain“, welche als negativer Regulator für die Cterminale Guanylatcyclase-Domäne gilt. Die Rezeptorbindung der NPs an die NPR-A und NPR-B erhöht die Produktion von intrazellulärem zyklischen Guanosinmonophosphat (cGMP), dem second-messenger der natriuretischen Peptide. Zyklisches Guanosinmonophosphat vermittelt dann die beschriebenen Funktionen der natriuretischen Peptide über cGMP-gesteuerte Proteinkinasen, Phosphodiesterasen und IonenKanäle.

Der Rezeptortyp NPR-A kommt am häufigsten im Endothel großer Gefäße vor und bindet ANP mit der höchsten Affinität, gefolgt von BNP (mit 10-fach niedrigerer Affinität) und CNP. Im Gegensatz dazu findet der NPR-B seine häufigste Ausprägung im Bereich des ZNS und in geringerer Konzentration auch in der Gefäßmuskulatur. Er bindet CNP mit der höchsten Affinität, gefolgt von ANP und BNP. In Nieren und Gefäßen findet man den NPR-C, welcher mit den natriuretischen Peptiden in folgender Reihenfolge interagiert: ANP > CNP > BNP. Dieser Rezeptortyp scheint über die bisher erwähnten Funktionen zusätzlich über einen Clearance-Mechanismus zu verfügen. Somit finden sich 95\% der Clearance-Rezeptoren in den Nieren und Gefäßen. Ergänzend können die Peptide auch enzymatisch abgebaut werden. Dieses erfolgt über membranständige, Zink enthaltende, neutrale Endopeptidase, welche sich vor allem in den Nieren, der Lunge, dem ZNS und den neutrophilen Granulozyten nachweisen lässt. Von den natriuretischen Peptiden besitzt das CNP die höchste Affinität zu den neutralen Endopeptidasen, gefolgt von ANP und BNP, wobei die Affinität zu ANP 
deutlich höher als die zu BNP ist. Die NEPs öffnen die Ringstruktur der natriuretischen Peptide und inaktivieren sie auf diese Weise. Dadurch, dass das BNP die niedrigste Affinität zu den Clearance-Rezeptoren und den neutralen Endopetidasen besitzt, erklärt sich die biologische Halbwertzeit, die mit 20 min ca. 7 mal länger ist als die des ANP, mit ca. 3 min. Längere HWZ weisen jedoch die Spaltprodukte der Peptidvorstufen auf. So besitzt NT-proANP 1-98 eine HWZ von ca. 1h und NT-proBNP 1-76 ca. 1-2 h (Mair et al. 2001, Ellis et al. 1998).

Zum jetzigen Zeitpunkt gibt es unterschiedliche Berichte über die in-vitro-Stabilität der natriuretischen Peptide. Es scheinen dabei verwendete Materialien einen Einfluss auf die Stabilität der natriuretischen Peptide zu haben. So sollte auf das Verwenden von Glasprodukten bei der Materialaufbewahrung verzichtet werden oder zuvor das Gefäß mit einem Silikonbezug beschichtet werden, da es sonst zur Absorption der NPs in oder an die Glaswand kommen kann. In EDTA-Rörchen ist ANP bei Raumtemperatur für 2-3 h stabil. Es sollte jedoch schnell zentrifugiert und das Plasma bei $-80{ }^{\circ} \mathrm{C}$ eingefroren werden. Dadurch bleibt ANP für mehrere Monate stabil. NT-proANP ist im EDTA-Plasma für vier Tage und im EDTA-Vollblut für drei Tage bei Raumtemperatur stabil. BNP ist dagegen im EDTA-Vollblut bei Raumtemperatur für $24 \mathrm{~h}$ stabil. Die Stabilität verlängert sich aber im EDTA-Plasma bei $-20{ }^{\circ} \mathrm{C}$ auf einen Monat. Nach drei Monaten bei $-20{ }^{\circ} \mathrm{C}$ fällt der BNP-Spiegel auf ca. $50 \%$ des Ausgangswertes. NTproBNP ist im EDTA-Plasma für 6-24 h stabil (Mair et al. 2001).

\subsection{Funktion, Eigenschaften und Sekretion der Surfactant Proteine}

Surfactant Proteine der Lunge sind eine komplexe Mischung aus Lipiden (90\%) und Proteinen (5-10\%), welche die große Oberflächenstruktur der Alveolarepithelien bedecken. Sie reduzieren dabei die Oberflächenspannung der Lunge, um den Kollaps der Lunge während der Respiration zu vermeiden. Surfactant wird von den Alveolarepithelzellen Typ II synthetisiert und in Organellen, den so genannten Lamellarkörperchen, gespeichert. Dieses wird dann in den Alveolarspalt abgegeben, wo es schließlich das so genannte tubuläre Myelin bildet, welches ein Zwischenprodukt des entstehenden Lipidfilms, der die Alveolen bedeckt, ist. Dipalmitoylphosphatidylcholin ist dabei 
die Hauptlipidkomponente des Surfactants mit einem über 90\%igen Hauptanteil aus Phospholipid (Kishore et al. 2006, Whittset und Weaver 2002, De Pasquale et al. 2004).

Es gibt vier Proteine des Surfactant, die eng mit den Surfactant-Lipiden in der Lunge assoziiert sind, SP-A, SP-B, SP-C und SP-D. SP-B (14kDa) und SP-C (6kDa) sind kleine und stark hydrophile Proteine, die eine wichtige Bedeutung in der Bildung der Phospholipidstrukur, Adsorption von der Luft-Lipid-Grenze, sowie bei der Erniedrigung der Oberflächenspannung der Alveolen besitzen. SP-B stabilisiert teilweise die Phospholipidstruktur durch seine Interaktion mit DPPC. Ähnlich soll SP-C bei der Stabilisierung der Phospholipidstruktur beteiligt sein (Kishore et al. 2006, Whittset und Weaver 2002, De Pasquale et al. 2004).

Surfctant Protein-A und SP-D sind große hydrophile Proteine. Ihre Basisstruktur beinhaltet eine N-terminale, dreifach-helikale Kollagenregion sowie eine homotrimere ligandenspezifische Domäne, die so genannte C-Type-Lectin- oder Carbohydrat-spezifische Region. Die SP-D-Konzentration im Surfactant der Alveolarepithelien ist zehnfach geringer als die des SP-A. Ungefähr 75\% des SP-D wird in der bronchoalveolären Lavage gefunden. Es bindet an Phosphatidylinositol sowie an Glucosylceramide. SP-A und SP-D scheinen eine wichtige Rolle beim Abwehrmechanismus von respiratorischen Pathogenen und Allergenen zu besitzen (Kishore et al. 2006, Whittset und Weaver 2002, De Pasquale et al. 2004).

Surfactant Protein-B ist das Kleinste der Surfactant Proteine, welche im Blut derzeit nachweisbar sind. In seiner Endform ist es hydrophob ( 5 bis $8 \mathrm{kDa}$ ), in seiner mittleren Form ist es hydrophil (26 bis $42 \mathrm{kDa}$ ) und im Blut nachweisbar. Surfactant Protein-B ist für die normale Lungenfunktion notwendig. Die bisher angenommene Bildung und Freisetzung erfolgt in den Alveolarepithelzellen Typ II sowie in den Clara-Zellen der Lunge, von welchen es in die Alveolen sezerniert wird. SP-B gelangt auch bei Beschädigung der alveolokapillären Membran durch einen Konzentrationsgradienten zwischen Alveoli und Blut ins Plasma (Kishore et al. 2006, Whittset und Weaver 2002, De Pasquale et al. 2004). 
Des Weiteren führt ein erhöhter Pmv z.B. im Rahmen eines kardialen Lungenödems zu einer strukturellen Läsion der alveolokapillären Membran, was als „stress failure“ (Belastungsfehler) bezeichnet wird und zu einer Ruptur der Komponenten der alveolokapillären Membran führt. Weiter konnte eine gesteigerte mikrovaskuläre Proteinpermeabilität, als sogenanntes ,,pore stretching“ nachgewiesen werden. Diese beiden Mechanismen führen zu einem weiteren Austritt von SP-B in das Plasma (De Pasquale et al. 2004, Hawgood 2004).

SP-D gehört zur Gruppe der C-type-Lectine mit Kollagenregionen. Es besteht aus vier Regionen, einem N-terminalen Cystein, an welches sich eine dreifach gefaltete Kollagenregion anschließt, welche von einer Alphahelix-Struktur fortgesetzt wird und in einem C-terminalen Ende mit C-type-Lectin endet. SP-D setzt sich zusammen aus Oligomeren mit einer Größe von 130 kDa, welche aus drei identischen Polypeptidketten von $43 \mathrm{kDa}$ bestehen. Menschliches SP-D ist in einer $520 \mathrm{kDa}$ tetramerischen Struktur mit vier Untereinheiten enthalten, die über ihr N-terminales Ende miteinander verknüpft sind (Kishore et al. 2006, Whittset und Weaver 2002).

Surfactant Protein-D scheint bei der Homöostase der Surfactant Proteine der Lunge eine Rolle zu spielen sowie die Immunantwort des Lungengewebes zu beeinflussen (Pastva et al. 2007, Shepherd 2002).

\subsection{Hypothese und Zielsetzung}

Die Hypothesen der Studie lauten wie folgt:

$\checkmark$ Erhöhte NT-proBNP-Plasmaspiegel erlauben im Vergleich zu anderen neuroendokrinen Markern mit hoher Sensitivität und Spezifität die rasche Diagnose der kardialen Ursache einer akuten Dyspnoe.

$\checkmark$ Erhöhte Surfactant-Protein-B- und Surfactant-Protein-D-Plasmaspiegel erlauben im Vergleich zu anderen neuroendokrinen Markern mit hoher Sensitivität und Spezifität die rasche Diagnose der pulmonalen Ursache einer akuten Dyspnoe. 
$\checkmark$ Erhöhte NT-proBNP-, Surfactan-Protein-B- und Surfactant-Protein-D-Plasmaspiegel erlauben im Vergleich zu anderen neuroendokrinen Markern mit hoher Sensitivität und Spezifität die rasche Diagnose der Ursache einer akuten Dyspnoe.

Ziel der Untersuchung ist, in einer prospektiven Analyse Patienten mit akuter Dyspnoe einer vollständigen klinischen und apparativen Diagnostik zuzuführen. Die entsprechende Diagnose (kardiale vs. nicht-kardiale Ursache) soll mit dem Ausmaß der neuroendokrinen Aktivierung, insbesondere dem NT-proBNP, Surfactant Protein-B und Surfactant Protein-D, in einen Zusammenhang gesetzt werden. Somit könnten für die Zukunft Laborparameter validiert werden, die die entsprechende technische Zusatzdiagnostik bereits frühzeitig in eine spezielle Richtung lenken können und so zur effektiven und kostensparenden Ressourcennutzung führen können. 


\section{Material und Methoden}

\section{$\underline{\text { 2.1. Patientenrekrutierung und Patientenzahl }}$}

Es wurden alle Patienten eingeschlossen, die sich unter Berücksichtigung der Ein- und Ausschlusskriterien, wegen einer akuten Dyspnoesymptomatik in der Notaufnahme des Klinikums der Georg-August-Universität-Göttingen vorstellten. Es wurden $81 \mathrm{~Pa}-$ tienten in die klinische Studie eingeschlossen.

\section{$\underline{\text { 2.1.1. Einschlusskriterien }}$}

$>$ Mindestens 18 Jahre

Einverständnisfähigkeit

\subsubsection{Ausschlusskriterien}

terminale oder akut dekompensierte schwere chronische Erkrankung (maligne Erkrankung, terminale Niereninsuffizienz) zum Zeitpunkt der Rekrutierung,

$>$ Demenz oder floride Psychose,

unzureichende Kommunikationsfähigkeit (schlechte Deutschkenntnisse, Aphasie)

\subsubsection{Studienablauf und Studiendesign}

Die Rekrutierung der Patienten erstreckte sich in dem Zeitraum vom 01.08.2002 bis zum 18.09.2004.

Im Rahmen der Aufnahme und Erstversorgung der Patienten in der Notaufnahme des Klinikums der Universität Göttingen wurden die Patienten in die klinische Studie „Wertigkeit von NT-proBNP, Surfactant Protein-B und Surfactant Protein-D als differentialdiagnostischer Parameter bei Patienten mit akuter Dyspnoe“ gemäß Studienprotokoll aufgeklärt und, bei schriftlicher Einwilligung, eingeschlossen. Es folgte eine 
sofortige Blutabnahme zur Bestimmung der neuroendokrinen Aktivierung. Unabhängig davon erhielten die Patienten die übliche klinische, laborchemische und apparative Diagnostik.

Die Studie ist eine randomisierte prospektive Doppelblind-Studie. Patienten und Probe erhielten eine Nummer. Die Entblindung der NT-proBNP, Surfactant-Protein-B- und Surfactant-Protein-D-Plasmaspiegel erfolgte nach der Zuordnung der Patienten in die unterschiedlichen Ursachengruppen der akuten Dyspnoe. Die Zuordnung in die Ursachengruppen der Dyspnoe vor Entblindung erfolgte unter Berücksichtigung der Anamnese, klinischen Symptomatik und der routinemäßigen diagnostischen Befunden in der Notaufnahme.

\subsubsection{Parameter zur differentialdiagnostischen Beurteilung der akuten Dyspnoe}

Zur differentialdiagnostischen Beurteilung wurden bei den rekrutierten Patienten folgende Daten erhoben:

$\checkmark$ vollständige klinische Untersuchung, Routinelaborparameter, Kreatininclearence, Echokardiografie, Röntgen-Thorax, wenn die letzte Aufnahme länger als 6 Monate zurücklag, weitere als notwendig erachtete Untersuchungen (z.B. Lungenszintigraphie, Spiral-CT), EKG, Alter, Geschlecht, Body Mass Index, Körperoberfläche, Auskultationsbefunde, Puls, Blutdruck

Vorerkrankungen:

KHK, Herzinsuffizienz, Klappenvitien, andere kardiale Erkrankungen, pulmonale Erkrankungen (z.B. COPD, Pleuraergüsse, Pneumothorax), arterielle Hypertonie, Diabetes mellitus, zerebrovaskuläre Erkrankungen, periphervaskuläre Erkrankungen, Hyperlipidämie, Familienanamnese, Hyperthyreose, nutritiv-toxische Anamnese (z.B. Alkoholabusus, Mangelernährung, Berufsanamnese) 
$\checkmark$ Raucher

○ ehemalig

○ aktuell

Sobald im Verlauf klinisch durchführbar:

$\checkmark$ Lungenfunktion.

\subsection{Probengewinnung}

Im Rahmen der Routineblutentnahme in der Notaufnahme des Klinikums der Universität-Göttingen wurden eine zusätzliche 4,5 ml Heparin-Monovette und eine $1.5 \mathrm{ml}$ EDTA-Monovette Blut abgenommen. Diese wurden unverzüglich bei $3000 \mathrm{U} / \mathrm{min}$ und Raumtemperatur für zehn Minuten zentrifugiert. Anschließend wurde das Plasma extrahiert und in gekennzeichneten Aliquots bei minus $79^{\circ} \mathrm{C}$ bis zur weiteren Messung eingefroren.

\subsection{Messung von NT-proBNP}

Die Messung des NT-proBNPs wurde durch einen ElectroChemiLumineszenz ImmunoAssay („ECLIA“) mittels Immunoassay Analyseautomaten Elecsys 2010 (Roche Diagnostics ${ }^{\circledR}$ ) und MODULAR ANALYTICS E170 (Elecsys Modul) durchgeführt.

Dies stellt einen immunologischen in vitro Test zur quantitativen Bestimmung von Nterminalen pro-BNP in Humanserum und -plasma dar.

Der Messbereich des Elecsys ${ }^{\circledR}$ Systems liegt zwischen 5-35.000 pg/ml bzw. 0.6-4130 pmol/1 (definiert durch die Nachweisgrenze und das Maximum der Masterkurve). Werte unterhalb der Nachweisgrenze werden als $<5 \mathrm{pg} / \mathrm{ml}$ bzw. $<0.6$ pmol/1 angegeben. Werte oberhalb des Messbereichs werden als $>35.000 \mathrm{pg} / \mathrm{ml}$ bzw. $>4130 \mathrm{pmol} / \mathrm{l}$ angegeben oder verdünnt (F2) entsprechend bis $70.000 \mathrm{pg} / \mathrm{ml}$ bzw. $8277 \mathrm{pmol} / 1$.

Das Aufmischen der Mikropartikel vor Gebrauch erfolgte automatisch. Die Testparameter über den auf den Reagenzien befindlichen Barcodes wurden eingelesen. 
Für die Messung mittels E170/Elecsys 2010 wurden die gekühlt gelagerte Reagenzien vor der Beladung auf ca. $20^{\circ} \mathrm{C}$ temperiert und in den Reagenzrotor $\left(20^{\circ} \mathrm{C}\right)$ des Gerätes platziert. Schaumbildung wurde dabei vermieden. Das Temperieren, Öffnen und Schließen der Flaschen sowie die Messungen erfolgten automatisch.

\subsubsection{Messung SP-B und SP-D}

Zur Bestimmung von Surfactant Protein-B wurde ein ELISA-inhibition-assay (kompetitive Inhibition) wie von Doyle et al. (1995) zur Bestimmung von Surfactant ProteinA beschrieben verwendet. Dabei wurde zur Isolation von Surfactant Protein-B $125 \mu 1$ Blutserum mit $500 \mu 10$ mM Tromethamin verdünnt. Nach 10 minütiger Zentrifugation bei Raumtemperatur wurden $125 \mu$ l einer Lösung von 3\% Natriumlaurylsulfat und 12\% Triton X-100 (vol/vol) hinzugegeben und für weitere 10 Minuten zentrifugiert.

Die Lösung wurde in ELISA Platten mit polyklonalen Antikörpern Po-B inkubiert (No. 2595; Costar, Cambridge, MA).

Durch eine zweite ELISA Platte, welche mit Surfactant Protein-B beschichtet wurde, konnten durch Verwendung Alkalin-Phosphatase-konjugierter IgG gegen Hasenimmunoglobuline und $15 \mathrm{mM}$ Disodium p-Nitrophenyl-Phosphat in 1,0 mM Diethanolamin sowie 0,5 $\mathrm{mM}$ Magnesiumchlorid als Substrat freie Antikörper bestimmt werden. Nach 30 Minuten wurde die Absorption des Substrates bei einer Wellenlänge von 405 nm durch Bio-Rad EIA Messer (Model 2550; Bio-Rad Laboratories, Richmond CA) bestimmt. Ein „Microman“ ELISA-Platten-Messprogramm (Bio-Rad Laboratories) wurde benutzt, um eine Standardkurve zu rekonstruieren und die Konzentration von SP-B in jeder Probe zu berechnen. Alle Proben wurden dupliziert und in vier fortlaufenden Verdünnungen bestimmt. Standards, in vierfacher Ausführung, waren in jeder ELISA Platte in acht verschiedenen Verdünnungen enthalten. (Messbereich 7,8 bis $1000 \mathrm{ng} / \mathrm{ml}$; r > 0.98) (Doyle et al. 1995, Doyle et al. 1997).

Zur Bestimmung des Surfactant Protein-D wurde ein kommerzielles ELISA System spezifisch für SP-D verwendet (BioVendor, Heidelberg, Deutschland). Die Tests wurden nach den Angaben des Herstellers mit einem Messbereich von 1.56 bis $100 \mathrm{ng} / \mathrm{ml}$ 
verwendet. Bei Werten über 100 ng/ml wurde die Probe weiter verdünnt und die Konzentration entsprechend des Verdünnungsfaktors berechnet.

Dieser Test ist ein Sandwich-ELISA-System zur Bestimmung des humanen SP-D. Für diesen Assay wurden die Proben in mit monoklonalen anti-humanen SP-D Antikörpern beschichteten Mikrotitervertiefungen (96 wells) inkubiert. Nach der Inkubation über Nacht wurde das Substrat mit dem mitgelieferten Waschpuffer dreimalig ausgewaschen. Anschließend wurde ein Meerrettich-Peroxidase-Konjugat hinzugefügt und für 120 Minuten inkubiert. Nach einem erneuten dreimaligen Auswaschen konnte das Meerrettich-Peroxidase-Konjugat mit dem mitgelieferten Lösungsmittel (Tetramethylbenzidin) reagieren. Die Reaktion wurde nach 20 Minuten durch die Zugabe einer sauren Lösung gestoppt. Anschließend wurde die Absorption mit einem „microplate“ Leser bei $450 \mathrm{~nm}$ gemessen. Der Absorptionsgrad ist proportional zur Konzentration des SP-D. Eine Standardkurve wurde durch das Aufzeichnen eines Absorptionswerts gegen ein Standardmaterial vom Hersteller ermittelt. Die Konzentrationen unbekannter Proben wurden durch das Benutzen der Standardkurven bestimmt. Die Antikörper waren kreuzreaktiv für Pferde, Affen, Schweine und Schafe.

\subsubsection{Validierung der Messverfahren}

Die Serum- bzw. Plasmaproben wurden beschriftet und nach der Zentrifugation bei Raumtemperatur und $3000 \mathrm{U} / \mathrm{min}$ bis zur Messung bei $-79^{\circ} \mathrm{C}$ eingefroren.

Die in der Routinediagnostik eingesetzten Standardverfahren benötigen keine weitergehende Validierung. Die Assays zur Bestimmung der Plasmaspiegel neuroendokriner Marker wurden bereits von der Herstellerfirma (Roche ${ }^{\circledR}$ Diagnostics, BioVendor) evaluiert und zusätzlich in der Abteilung für klinische Chemie der Universität Göttingen einer analytischen Überprüfung unterzogen.

Um die Reproduzierbarkeit der SP-B-Messergebnisse zu bestimmen, wurde eine Probe 15-fach gemessen. Die Assay-Variabilitäten innerhalb einer Platte wurden durch die Analyse von 16 reproduzierten Patientenproben untersucht (Doyle et al. 1997).

Auch bei der Messung der SP-D- Konzentration mittels kommerziellem ELISA wurde die Zuverlässigkeit der Messergebnisse überprüft. Die dem Kit beiliegenden 
Kontrollproben wurden bei jeder Messung analysiert. Die Ergebnisse wurden nur verwendet, wenn die Werte der Kontrollproben in den vom Hersteller festgelegten Bereichen lagen.

\subsection{Echokardiografie}

Die echokardiografischen Untersuchungen erfolgten in der Abteilung Kardiologie und Pneumologie der Georg-August-Universität Göttingen am Aufnahmetag. Die Echokardiografie wurde von erfahrenen Untersuchern unter Verwendung standardisierter Techniken gemäß der American Society of Echocardiography durchgeführt (Sonos 550, Philips, 4 MHz-Schallkopf) (Biering et al. 2005).

\subsection{Statistische Datenerhebung und Verarbeitung}

Es handelt sich bei dieser Studie um eine prospektive klinische Studie. Die Untersucher waren gegenüber den Plasmakonzentrationen der natriuretischen Peptide sowie der Surfactant Proteine geblindet. Klinische Faktoren zwischen den vier Gruppen wurden mittels Kruskal-Wallis -Test unter Verwendung des $\chi^{2}$-Test erhoben. Die Signifikanz wurde als $\alpha=5 \%$ festgelegt.

Lineare Diskriminanzanalysen (LDA) wurden verwendet, um die Gruppen der Luftnot unter Berücksichtigung von NT-proBNP, SP-D oder SP-B zu klassifizieren. All diese Gruppen, ink1. Alter, wurden zusätzlich der multiplen LDA unterzogen. Die Klassifikationsgenauigkeit, i.S. der richtig klassifizierten Patienten, wurde mittels Leave-oneout Kreuzvalidierung evaluiert. Statistische Analysen wurden zum Teil mit SAS (V9.1, SAS Institute) und teilweise mit freier Software R V2.6 (www.r-project.org) vollzogen. 


\section{$\underline{\text { 3. Ergebnisse }}$}

\subsection{Subgruppen der akuten Dyspnoe}

Wir klassifizierten die Patienten in vier Subgruppen in Bezug auf die Ursache der akuten Dyspnoe: (1) „,kardial“ ( $\mathrm{n}=43)$, (2) „pulmonal“ ( $\mathrm{n}=18)$, (3) „kardiopulmonal“ ( $\mathrm{n}=$ 10) und (4) „extrakardiopulmonal“ ( $\mathrm{n}=10)$. Diese Einteilung erfolgte mit Hilfe der klinischen Routinediagnostik und der zur Verfügung stehenden Befunde.

In Tabelle 2 werden Serumplasmaspiegel des NT-proBNP, SP-D und SP-B sowie das Alter und der BMI aller Patientengruppen festgehalten. Interessant ist, dass die NTproBNP Plasmakonzentrationen in den Gruppen der kardialen- sowie der kardiopulmonalen Ursachen der akuten Dyspnoe signifikant $(p<0,01)$ höher waren als in den übrigen Gruppen. Zusätzlich zeigt sich eine signifikant höhere Plasmakonzentration des SP-D $(p<0,05)$ in der Gruppe der kardial bedingten akuten Dyspnoe im Vergleich mit den übrigen Gruppen. Die SP-B Plasma-Konzentrationen zeigten keinen signifikanten Unterschied zwischen den einzelnen Subgruppen der akuten Dyspnoe.

\begin{tabular}{|c|c|c|c|c|c|}
\hline Parameter & $\begin{array}{c}\text { kardial } \\
(\text { Mittelwerte } \pm \\
\text { SD } \mathrm{n}=43)\end{array}$ & $\begin{array}{c}\text { pulmonal } \\
\text { (Mittelwerte } \pm \\
\text { SD } \mathrm{n}=18)\end{array}$ & $\begin{array}{c}\text { kardio- } \\
\text { pulmonal } \\
\text { (Mittelwerte } \pm \\
\text { SD } \mathrm{n}=10)\end{array}$ & $\begin{array}{c}\text { extrakardio- } \\
\text { pulmonal } \\
(\text { Mittelwerte } \pm \\
\text { SD } \mathrm{n}=10)\end{array}$ & p \\
\hline $\begin{array}{c}\text { NTproBNP } \\
(\mathbf{p g} / \mathbf{m l})\end{array}$ & $4020,3 \pm 4585$ & $3114,2 \pm 8506$ & $5604,2 \pm 3368$ & $691,6 \pm 1577$ & $<0,0001$ \\
\hline SP-B (ng/ml) & $23184,9 \pm 8024$ & $24170,2 \pm 7389$ & $29115,6 \pm 10872$ & $24381,6 \pm 8897$ & 0,4051 \\
\hline SP-D (ng/ml) & $145.6 \pm 93,3$ & $103.8 \pm 63,4$ & $108.8 \pm 86,7$ & $68.8 \pm 21,3$ & 0,0061 \\
\hline Alter (Jahren) & $72.6 \pm 11,5$ & $62.8 \pm 14,3$ & $71.8 \pm 9.6$ & $57.0 \pm 18$ & 0,0034 \\
\hline BMI & $28.1 \pm 1.0$ & $26.2 \pm 1.0$ & $25.2 \pm 1.3$ & $29.6 \pm 1.8$ & 0,2566 \\
\hline
\end{tabular}

Tabelle 2: Mittelwerte der Serumplasmaspiegel von NTproBNP, SP-B und SP-D mit Standardabweichenung sowie Alter und Body-Mass-Index der einzelnen Subgruppen der akuten Luftnot 
Es fand sich ein signifikanter Unterschied beim Alter $(\mathrm{p}<0,05)$ zwischen den einzelnen Untergruppen der akuten Dyspnoe. In der kardialen Gruppe (72,6 Jahre $\pm 11,5)$ sowie in der kardiopulmonalen Gruppe (71,8 Jahre \pm 9,6) der akuten Dyspnoe zeigte sich ein signifikant älteres Patientenkollektiv als in den übrigen Subgruppen der akuten Dyspnoe (Tabelle 2).

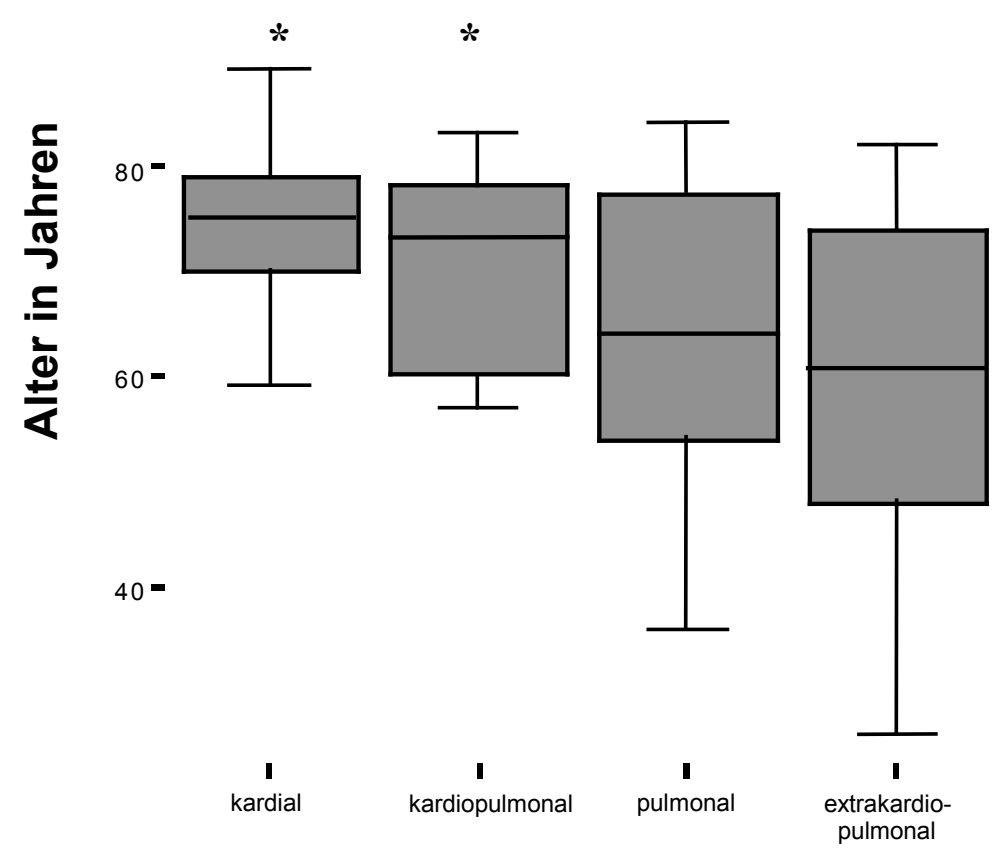

Abbildung 1: Das Alter in Abhängigkeit von der Ursache der akuten Dyspnoe (Box-Plot mit Median, 25.,und 75. Perzentile: graue Box; 5. und 95. Perzentile: horizontale Striche). * signifikanter $(\mathrm{p}<0,05)$ Unterschied im Alter zwischen der kardialen und kardiopulmonalen Gruppen der akuten Dyspnoe und den nicht kardialen Subgruppen der akuten Dyspnoe

In Tabelle 3 werden die Charakteristika des Gesamtkollektivs sowie der einzelnen Subgruppen der akuten Dyspnoe gegenübergestellt. Die Gruppen mit einer kardialen Genese der akuten Dyspnoe hatten einen höheren Anteil an Patienten mit einer arteriellen Hypertonie als die übrigen Patientengruppen. 


\begin{tabular}{|ccccccc|}
\hline Parameter & $\begin{array}{c}\text { Gesamt- } \\
\text { kollektiv }\end{array}$ & kardial & pulmonal & $\begin{array}{c}\text { extra- } \\
\text { kardio- } \\
\text { pulmonal }\end{array}$ & $\begin{array}{c}\text { kardio- } \\
\text { pulmonal }\end{array}$ & $\left(\chi^{2}\right.$ test $)$ \\
N & 81 & 43 & 18 & 10 & 10 & \\
Alter (Jahre, mean \pm & $68,4 \pm 13,9$ & $72,6 \pm 11,5$ & $62,8 \pm 14,3$ & $71,8 \pm 9,6$ & $57,0 \pm 18$ & 0.0034 \\
$\begin{array}{c}\text { SD) } \\
\text { Männliches Geschlecht } \\
\text { (\%) }\end{array}$ & 54 & 54 & 66 & 70 & 70 & 0.1229 \\
$\begin{array}{c}\text { BMI (kg/m2, mean } \pm \\
\text { SD) }\end{array}$ & $28 \pm 1$ & $28,1 \pm 1$ & $26,2 \pm 1$ & $25,2 \pm 1,3$ & $29,6 \pm 1,8$ & 0.2566 \\
$\begin{array}{c}\text { Nikotinabusus (\%) } \\
\text { Diabetes }\end{array}$ & 33 & 34 & 28 & 30 & 22 & 0.6358 \\
$\begin{array}{c}\text { mellitus (\%) } \\
\text { Hypertonie (\%) }\end{array}$ & 23 & 26 & 11 & 41 & 16 & 0.3052 \\
Hypercholesterinämie & 60 & 76 & 34 & 50 & 44 & 0.0061 \\
$(\%)$ & 23 & 32 & 11 & 0 & 16 & 0,0638 \\
\hline
\end{tabular}

Tabelle 3: Patientencharakteristika des Gesamtkollektivs sowie der Untergruppen der Ursachen der akuten Dyspnoe

\subsection{Patienten mit kardialer Ursache der akuten Dyspnoe}

Das Durchschnittsalter der Patienten mit einer kardialen Ursache der Dyspnoe lag bei 72,6 Jahren (SD \pm 11,5 Jahre, $\mathrm{n}=43, \mathrm{~m}=18, \mathrm{w}=25)$. Der mittlere NT-proBNPPlasmaspiegel lag bei 4020,3 pg/ml (SD $\pm 4585,7$ pg/ml, $\mathrm{n}=43)$, der mittlere Surfactant-Protein-B-Plasmaspiegel bei 23184,9 ng/ml (SD $\pm 8024,2 \mathrm{ng} / \mathrm{ml}, \mathrm{n}=43)$ und der mittlere Surfactant-Protein-D-Plasmaspiegel bei $145.6 \mathrm{ng} / \mathrm{ml}(\mathrm{SD} \pm 93,3 \mathrm{ng} / \mathrm{ml}$, $n=43)$.

Es findet sich ein signifikanter Unterschied der Serumplasmaspiegel des Surfactant Protein-D $(\mathrm{p}<0,05)$ zwischen der Gruppe mit einer kardialen Ursache der Dyspnoe und der pulmonalen, extrakardiopulmonalen und gemischt kardiopulmonalen Gruppe der akuten Dyspnoe. Dabei zeigten sich in der Gruppe der kardialen Ursache der akuten Dyspnoe signifikant höhere Serumplasmaspiegel des SP-D als in den übrigen Subgruppen. 


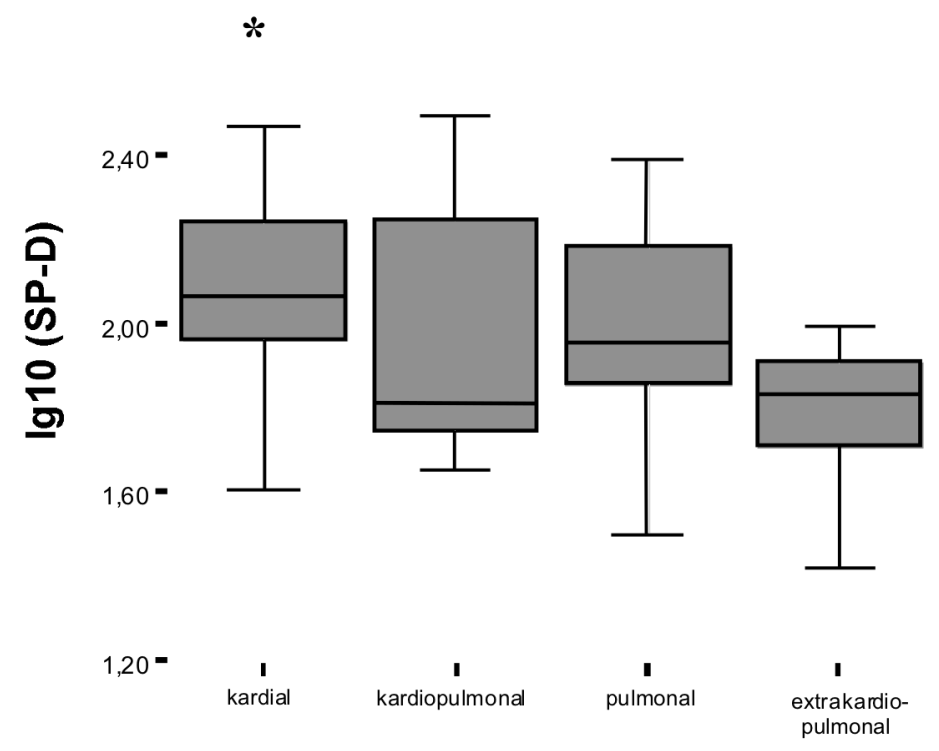

Abbildung.2: Surfactant-Protein-D-Plasmaspiegel in logarithmischer Auftragung (ng/ml) in Abhängigkeit von der Ursache der akuten Dyspnoe (Box-Plot mit Median, 25.,und 75. Perzentile: graue Box; 5. und 95. Perzentile: horizontale Striche). *signifikanter Unterschied $(\mathrm{p}<0,05)$ zwischen der kardialen- und den übrigen Ursachengruppen der akuten Dyspnoe.

\subsection{Patienten mit kardiopulmonaler Ursache der akuten Dyspnoe}

Die Patienten mit einer gemischt kardiolpulmonalen Ursache der akuten Dyspnoe waren im Mittel 71,8 Jahre alt (S.D \pm 9,6 Jahre, $n=10, m=7, w=3)$. Der mittlere NTproBNP-Plasmaspiegel lag bei 5604,2 pg/ml (SD $\pm 3367,6 \mathrm{pg} / \mathrm{ml}, \mathrm{n}=10)$, der mittlere Surfactant-Protein-B-Plasmaspiegel bei 29115,6 ng/ml (SD $\pm 10871,9 \mathrm{ng} / \mathrm{ml}, \mathrm{n}=10)$, und die mittlere SP-D Konzentration bei 108,8 $\mathrm{ng} / \mathrm{ml}(\mathrm{SD} \pm 86,7 \mathrm{ng} / \mathrm{ml}, \mathrm{n}=10)$.

Es zeigte sich, dass in den Gruppen mit einer kardialen sowie gemischt kardiopulmonalen Ursache der akuten Luftnot signifikant höhere NT-proBNP Plasmaspiegel $(p<0,01)$ im Vergleich mit den Untergruppen einer extrakardialen und pulmonalen Ursache einer akuten Dyspnoe auftreten. 


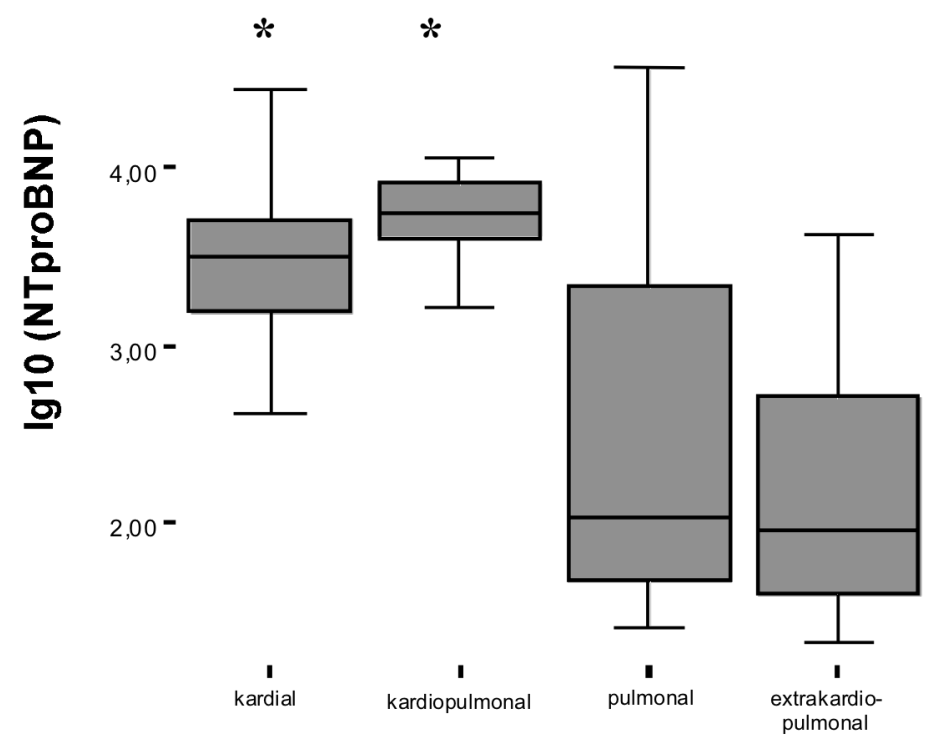

Abbildung.3: NT-proBNP-Plasmaspiegel mit logarithmischer Auftragung (pg/ml) in Abhängigkeit von der Ursache der Dyspnoe (Box-Plot mit Median, 25.,und 75. Perzentile: graue Box; 5. und 95. Perzentile: horizontale Striche)

* signifikanter Unterschied $(\mathrm{p}<0,05)$ zwischen der kardialen- und kardiopulmonalen Gruppe und den übrigen Ursachengruppen der akuten Dyspnoe.

\subsection{Patienten mit pulmonaler Ursache der akuten Dyspnoe}

Die Patienten mit einer pulmonalen Ursache der Dyspnoe waren im Mittel 62,8 Jahre alt ( $\mathrm{SD} \pm 14,3$ Jahre, $\mathrm{N}=18, \mathrm{~m}=12$, $\mathrm{w}=6$ ). Der mittlere NT-proBNP-Plasmaspiegel lag bei $3114,2 \mathrm{pg} / \mathrm{ml}$ (SD $\pm 8506,2 \mathrm{pg} / \mathrm{ml}, \mathrm{n}=18)$. Der mittlere Surfactant-Protein-BPlasmaspiegel lag bei $24170,2 \mathrm{ng} / \mathrm{ml}(\mathrm{SD} \pm 7389 \mathrm{ng} / \mathrm{ml}, \mathrm{n}=18)$, die mittlere SP-DPlasmakonzentration bei $103,8 \mathrm{ng} / \mathrm{ml}(\mathrm{SD} \pm 63,4 \mathrm{ng} / \mathrm{ml}, \mathrm{n}=18)$.

\subsection{Patienten mit extrakardiopulmonaler Ursache der akuten Dyspnoe}

Die Patienten mit einer extrakardiopulmonalen Ursache der akuten Luftnot waren im Mittel 57,0 Jahre alt ( $\mathrm{SD} \pm 18$ Jahre $\mathrm{n}=10, \mathrm{~m}=7, \mathrm{w}=3)$. Der mittlere NT-proBNPPlasmaspiegel lag bei $691,6 \mathrm{pg} / \mathrm{ml}(\mathrm{SD} \pm 1576,5 \mathrm{pg} / \mathrm{ml}, \mathrm{n}=10)$. Der mittlere Surfactant Protein-B-Plasmaspiegel lag bei 24381,6 ng/ml (SD $\pm 8897,4 \mathrm{ng} / \mathrm{ml}, \mathrm{n}=10)$. Der durchschnittliche SP-D Wert betrug 68,8 ng/ml (SD $\pm 21,3 \mathrm{ng} / \mathrm{ml}, \mathrm{n}=10)$.

Es zeigte sich kein Unterschied des Surfactamt-Protein-B-Plasmaspiegels zwischen den einzelnen Untergruppen bei Patienten mit akuter Dyspnoe. 


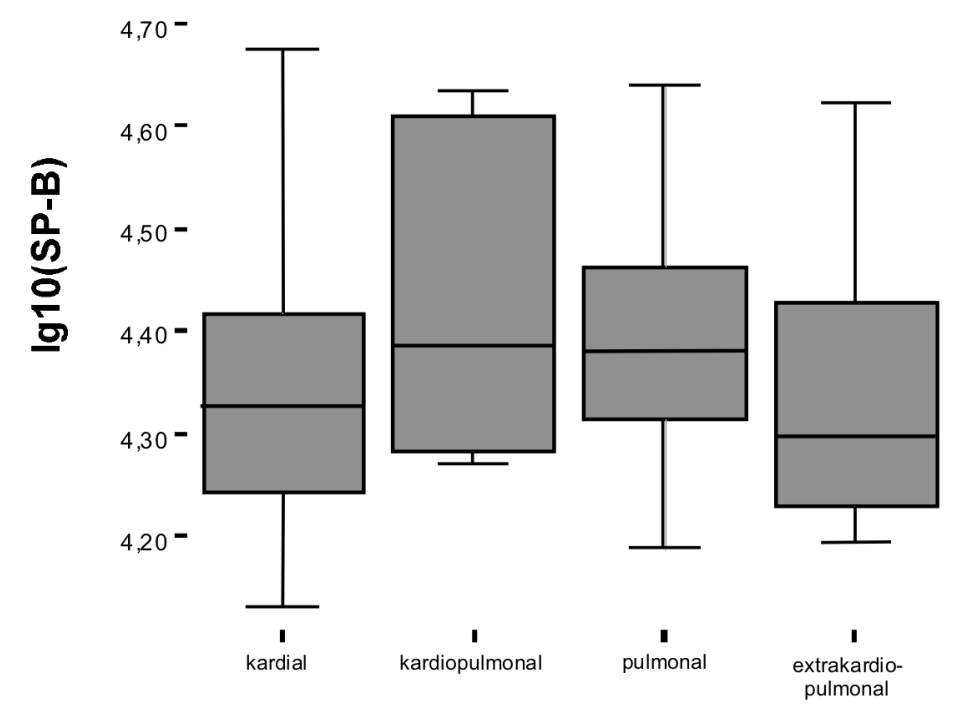

Abbildung.4: Surfactant Protein-B-Plasmaspiegel logarithmischer Auftragung (ng/ml) in Abhängigkeit von der Ursache der akuten Dyspnoe (Box-Plot mit Median, 25.,und 75. Perzentile: graue Box; 5. und 95. Perzentile: horizontale Striche). Kein signifikanter Unterschied zwischen den Ursachengruppen.

\subsection{Klassifikation der Ursachen der akuten Dyspnoe}

Diejenigen Parameter, die sich zwischen den Subgruppen der akuten Dyspnoe als signifikant herausgestellt haben, wurden zur Klassifikation mittels Diskriminanzanalyse verwendet. Dies waren NTproBNP, SP-D und das Alter.

Mit diesen Parametern konnten 41 Patienten (52\%) richtig in ihre Subgruppen der Ursache der akuten Dyspnoe klassifiziert werden. Dabei lag die beste Korrelation in der kardialen, kardiopulmonalen und extrakardiopulmonalen Gruppe der akuten Dyspnoe mit $60 \%$ richtig klassifizierten Patienten sowie die schlechteste Korrelation in der Gruppe der pulmonalen Ursache der akuten Dyspnoe mit 4 Patienten (22\%).

Die folgende Tabelle gibt die Anzahl an korrekten bzw. falschen Zuordnungen bei einer Reklassifikation wieder.

\begin{tabular}{|l|c|c|c|c|}
\hline Gruppe & kardial & pulmonal & $\begin{array}{c}\text { kardio- } \\
\text { pulmonal }\end{array}$ & $\begin{array}{c}\text { extrakardio- } \\
\text { pulmonal }\end{array}$ \\
\hline Anzahl (n) & 43 & 18 & 10 & 10 \\
\hline $\begin{array}{l}\text { richtig } \\
\text { klassifiziert }\end{array}$ & $26(60 \%)$ & $4(22 \%)$ & $6(60 \%)$ & $6(60 \%)$ \\
\hline
\end{tabular}

Tabelle 4: Klassifikation mit linearer Diskriminanzanalyse (52\% gesamt richtig klassifiziert) unter Verwendung NT-proBNP, Alter und SP-D 
Die Diskriminanzanalyse zur Klassifikation von Patienten der vier Subgruppen der akuten Dyspnoe anhand der NT-proBNP-Plasmaspiegel zeigte in der Gesamtgruppe 32 Patienten (40\%) korrekt klassifiziert. Dabei lag die höchste Rate der richtig klassifizierten Patienten anhand des NT-proBNP-Plasmaspiegels in der Gruppe der kardiopulmonalen Ursache der Dyspnoe mit 8 (80\%). Die niedrigste Klassifikation zeigte sich in der Patientengruppe mit einer pulmonalen Ursache der akuten Luftnot mit 1 (5\%). Bei der Subgruppe der kardial bedingten akuten Dyspnoe wurden 17 (40\%) und bei der Patientengruppe mit einer extrakardio-pulmonalen Ursache der akuten Luftnot $6(60 \%)$ richtig klassifiziert.

\begin{tabular}{|l|c|c|c|c|}
\hline Gruppe & kardial & pulmonal & $\begin{array}{c}\text { kardio- } \\
\text { pulmonal }\end{array}$ & $\begin{array}{c}\text { extrakardio- } \\
\text { pulmonal }\end{array}$ \\
\hline Anzahl (n) & 43 & 18 & 10 & 10 \\
\hline $\begin{array}{l}\text { richtig } \\
\text { klassifiziert }\end{array}$ & $17(40 \%)$ & $1(5 \%)$ & $8(80 \%)$ & $6(60 \%)$ \\
\hline
\end{tabular}

Tabelle 5: Klassifikation mit linearer Diskriminanzanalyse (40\% gesamt richtig klassifiziert) unter Verwendung von NTproBNP

In den Subgruppen mit einer kardialen Ursache der Luftnot wurde für die AUC der Plasmakonzentrationen des NT-proBNP ein Wert von 0,83 [0,72 - 0,95] bestimmt. Der optimale „cut-off“ lag bei 982,8 pg/ml. Hier beträgt die Sensitivität 89\%, die Spezifität $79 \%$, der negativ prädiktive Wert 79\% und der positiv prädiktive Wert $89 \%$ für eine kardiale Ursache der akuten Dyspnoe. 


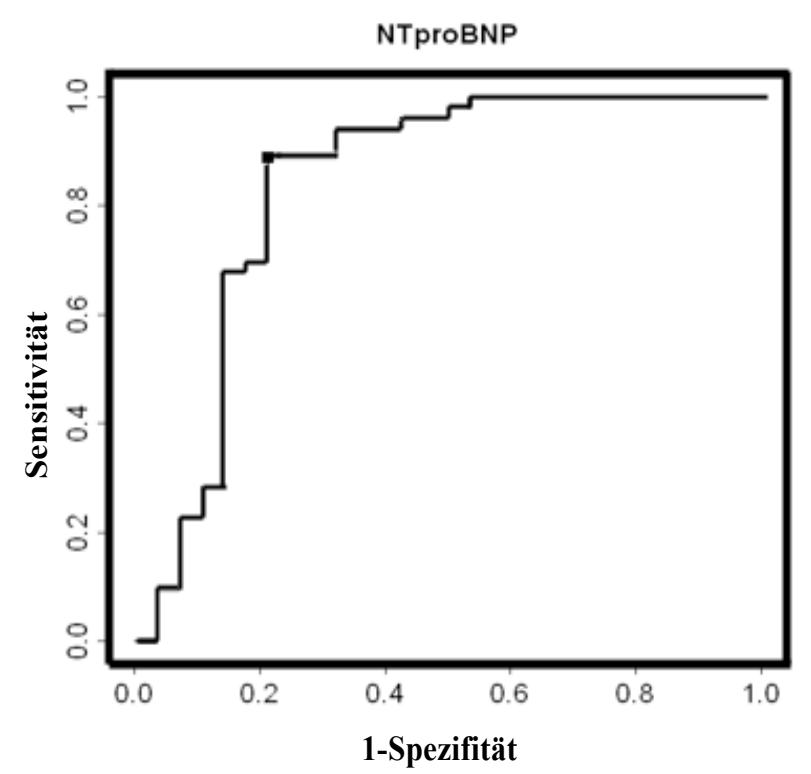

Abb.5: „Receiver operator characteristics“ (Roc) Kurve des NT-proBNP (pg/ml) zur Detektion einer kardialen Ursache der akuten Luftnot.

In den Subgruppen der Patienten mit einer kardialen Ursache der Luftnot zeigte sich im Vergleich zu den NT-proBNP-Plasmaspiegeln für das SP-D eine niedrigere AUC mit 0,68 [0,56 - 0,80]. Weiterhin zeigte sich eine Sensitivität von 68\%, eine Spezifität von $71 \%$, ein negativ prädiktiver Wert von $54 \%$ und ein positiv prädiktiver Wert von $82 \%$ bei einem ,cut-off"-Wert von $92 \mathrm{ng} / \mathrm{ml}$ hinsichtlich einer kardialen Ursache der Luftnot.

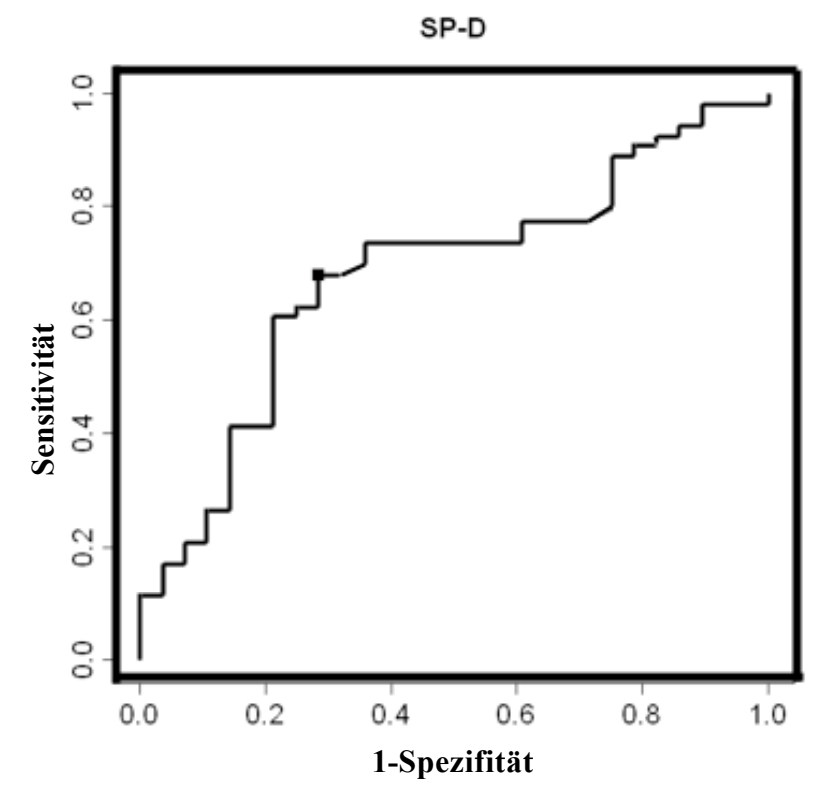

Abb.6:,,Receiver operator characteristics“ (Roc) Kurve des SP-D (ng/ml) zur Detektion einer kardialen Ursache der akuten Luftnot 
Tabelle $6 \mathrm{a}$ und $6 \mathrm{~b}$ zeigen den positiv und negativ prädiktiven Wert sowie die Spezifität und Sensitivität für NT-proBNP, SP-D und das Alter zur Detektion einer kardialen Genese der akuten Dyspnoe.

\begin{tabular}{|c|c|c|c|c|}
\hline Parameter & Sensitivität & Spezifität & $\mathbf{A U C}$ & cut-off \\
\hline $\begin{array}{l}\text { NTproBNP } \\
\text { (pg/ml) }\end{array}$ & $\begin{array}{l}0,89 \\
{[0,78-0,96]}\end{array}$ & $\begin{array}{l}0,79 \\
{[0.59-0,92]}\end{array}$ & $\begin{array}{l}0,83 \\
{[0,72-0,95]}\end{array}$ & 982,8 \\
\hline SP-D (ng/ml) & $\begin{array}{l}0,68 \\
{[0,54-0,80]}\end{array}$ & $\begin{array}{l}0,71 \\
{[0.51,0,87]}\end{array}$ & $\begin{array}{l}0,68 \\
{[0.56-0,80]}\end{array}$ & 92 \\
\hline Alter (Jahre) & $\begin{array}{l}0,79 \\
{[0,66-0,89]}\end{array}$ & $\begin{array}{l}0,64 \\
{[0,44-0,81]}\end{array}$ & $\begin{array}{l}0,73 \\
{[0,61-0,85]}\end{array}$ & 68 \\
\hline
\end{tabular}

Tabelle 6a : AUC, Sensitivität, Spezifität, für die Plasmakonzentration des NT-proBNP, SP-D und des Alters zur Diagnose der kardialen Ursache der akuten Luftnot

\begin{tabular}{|l|l|l|l|}
\hline Parameter & $\begin{array}{l}\text { positiv } \\
\text { prädiktiver Wert }\end{array}$ & $\begin{array}{l}\text { negativ } \\
\text { prädiktiver Wert }\end{array}$ & richtig klassifiziert \\
\hline NTproBNP (pg/ml) & 0,89 & 0,79 & $85 \%$ \\
& {$[0,78-0,96]$} & {$[0,59-0,92]$} & \\
\hline SP-D (ng/ml) & 0,82 & 0,54 & $69 \%$ \\
& {$[0,67-0,92]$} & {$[0,37-0,71]$} & \\
\hline Alter (Jahre) & 0.81 & 0,62 & $74 \%$ \\
& {$[0,67-0,90]$} & {$[0,42-0,79]$} & \\
\hline
\end{tabular}

Tabelle 6b: negativ und positiv prädiktiver Wert für die Plasmakonzentration des NT-proBNP, SP-D und des Alters zur Diagnose der kardialen Ursache der akuten Dyspnoe. 


\section{$\underline{\text { 4. Diskussion }}$}

Die akute Dyspnoe geht mit verschiedenen kardiorenalen, hämodynamischen sowie neurohormonellen Veränderungen und ggf. in der Folge mit einer hohen Morbidität und Mortalität einher. Nachdem erstmals erhöhte Plasmaspiegel von NT-proBNP bei der Herzinsuffizienz gemessen worden sind, begannen verschiedene Untersuchungen zur diagnostischen Aussagekraft und prognostischen Wertigkeit der neurohormonalen Aktivierung bei Patienten mit akuter Luftnot. Allgemein zeigte sich dabei die kardiopulmonale Diagnostik als zeitaufwändig und nicht immer diagnose- bzw. symptomkorreliert. Es konnte in verschiedenen Studien gezeigt werden, dass die Bestimmung von natriuretischen Peptiden in der Notaufnahme zusammen mit klinischen Parametern die Zeit bis zur Diagnosefindung und zum Therapiebeginn verkürzen kann. Zudem können die Aufenthaltsdauer im Krankenhaus, auf der Intensivstation und die Behandlungskosten gesenkt werden. Weiterhin konnte gezeigt werden, dass bei Patienten mit Luftnot auf Grund einer kardialen oder pulmonalen Grunderkrankung die schnelle Diagnostik und Behandlung die Morbidität und Mortalität reduzieren können (Müller et al. 2004, Moe et al. 2007).

Die natriuretischen Peptide können die Behandlungskosten, welche 1997 in den USA auf 5,5 Millionen US\$ geschätzt wurden, um ca. 26\% senken (Müller et al. 2004). BNP und NT-proBNP scheinen die aussagekräftigsten neurohumoralen Prädiktoren für die linksventrikuläre Funktion und ein prognostischer Marker der Herzinsuffizienz zu sein (Throughton et al. 2000, Richards et al. 1998, Maisel et al. 2002).

Die Freisetzung der neurohumoralen Peptide erfolgt bei einer Erhöhung der kardialen Wandspannung aus den Myozyten sowie bei einer erhöhten Volumen- und Druckbelastung (Trougthon et al. 2000, Müller et al. 2004). Verschiedene Studien haben die Aussagekraft des NT-proBNP als differentialdiagnostischen Marker der akuten Luftnot in der Notaufnahme untersucht (Januzzi et al 2005, Ray et al. 2004, McCullough et al. 2002). Wie in unserer Studie zeigte sich in diesen Studien ein vergleichbar hoher 
Aussagewert der natriuretischen Peptide für eine kardiale Ursache der akuten Dyspnoe.

Wir untersuchten die Wertigkeit des NT-proBNP, SP-B und SP-D Plasmaspiegels für die Differentialdiagnose der akuten Dyspnoe. Diese Studie zeigt an einem sehr heterogenen Patientenkollektiv, dass, wie von uns vermutet und übereinstimmend mit den Ergebnissen vorheriger Studien, die Bestimmung der natriuretischen Peptide einen wertvollen Beitrag zur Behandlung der akuten Luftnot in der Notaufnahme leisten kann (Januzzi et al. 2005, Troughton et al. 2000, Luchner et al. 2003, Müller et al. 2004, Mark et al. 2004).

In unserer Studie findet sich in der Gruppe der Patienten mit einer kardialen Ursache sowie einer kardiopulmonalen Ursache der Luftnot ein signifikant höherer Plasmaspiegel von NT-proBNP als in der Gruppe mit einer extrakardialen oder rein pulmonalen Ursache der akuten Dyspnoe.

Als ein Resultat unserer Studie konnten wir zeigen, dass der NTproBNPPlasmaspiegel eine gute Differenzierung zwischen einer kardial bzw. pulmonal bedingten Dyspnoe erlaubt.

Zusätzlich zeigte sich dabei ein signifikanter Unterschied im Alter der Patienten in der kardialen Gruppe der akuten Luftnot im Gegensatz zu den übrigen Subgruppen der akuten Dyspnoe. Es ist dabei zu berücksichtigen, dass in vorherigen Studien (Luchner et al. 2000, Luchner et al. 2002, Redfield et al 2002, Januzzi et al 2005, Januzzi et al 2006) ein Einfluss des Alters auf die Höhe des NT-proBNP-Serumspiegels beschrieben worden ist, weswegen altersabhängige cut-off-Werte des NT-proBNP für die Differentialdiagnose der akuten Dyspnoe sinnvoll erscheinen.

Unsere Studie ist die erste, welche die Wertigkeit der Plasma SP-B- und SP-D-Spiegel bei der akuten Dyspnoe untersucht.

Die Bedeutung von Surfactant-Protein-B und Surfactant-Protein-D bei Patienten mit akuter Dyspnoe ist derzeit noch Gegenstand laufender Studien. Pascual-Figal et al. (2009) konnte zeigen, dass SP-B-Plasmaspiegel bei Patienten mit chronischer Herzinsuffizienz und erniedrigter LVEF signifikant erhöht sind. Eine Untersuchung von De Pasquale et al. (2004) zeigte, dass der SP-B-Plasmaspiegel bei Patienten mit chronischer Herzinsuffizienz erhöht ist und mit dem Ausmaß der klinischen Symptome kor- 
reliert. Weiter konnte von Pasquale und Mitarbeitern gezeigt werden, dass die SP-BPlasmaspiegel bei ambulanten Patienten mit chronischer Herzinsuffizienz erhöht sind und, ähnlich dem NT-proBNP-Plasmaspiegel, mit zunehmender Dekompensation einer Herzinsuffizienz ansteigen. Es wird angenommen, dass die erhöhten SP-BPlasmaspiegel durch eine erhöhte alveolokapilläre Permeabilität und einen erhöhten mikrovaskulären Druck bei chronischer Herzinsuffizienz und chronischem Lungenödem bedingt sind (De Pasquale et al. 2004). Die Ergebnisse einer Studie von Doyle et al. (1997) zeigte, dass die Plasma-SP-B-Konzentration bei Patienten mit ARDS als Ausdruck einer akuten Schädigung der alveolokapillären Membran erhöht ist und als guter Marker einer akuten Lungenfunktionsstörung dienen kann.

Im Gegensatz zu den vorherigen Studien von DePasquale et al. (2004), Pascual-Figal et al (2009) und Doyle et al. (1997) fand sich in unserer Studie kein signifikanter Unterschied der SP-B-Plasmaspiegel zwischen den einzelnen Subgruppen der Ursache einer akuten Dypnoe. Die fehlende SP-B-Plasmaspiegelerhöhung bei Patienten mit akuter Dyspnoe ist möglicherweise auf eine geringere Schädigung der alveolokapillären Membran als bei Patienten mit chronischer Herzinsuffizienz zurückzuführen.

Dabei scheinen chronische Lungenfunktionsstörungen, unter anderem im Sinne eines chronischen Lungenödems bei chronischer Herzinsuffizienz, eine wesentliche Rolle zu spielen. Zusätzlich wurde bei Pascual-Figal und Mitarbeitern eine Bestimmung des SP-B-Plasmaspiegels mittels Western-Blot durchgeführt, welche eine höhere Spezifität als eine ELISA-Bestimmung zur Proteindetektion besitzt. Möglicherweise lassen sich mit der Western-Blot-Messung auch Plasmaspiegelveränderungen des SP-B bei akuter Dyspnoe nachweisen.

Die von Doyle et al. (1997) beschriebenen SP-B-Plasmaspiegelerhöhungen bei Patienten mit ARDS sind am ehesten auf eine initial starke, diffuse Lungenschädigung zurückzuführen.

Zusätzlich können Kofaktoren wie die Elimination und eine mögliche Kumulation der Surfactant-Proteine, bei chronischen kardiopulmonalen Veränderungen, als Einflussfaktoren auf die Surfactant-Protein-Serumspiegel eine Rolle spielen. Es bedarf dabei weiterer Untersuchungen um zu klären, ab wann strukturelle und hämodynamische Veränderungen der Lunge durch eine akute Dyspnoe zu einer Änderung der SP-B Sek- 
retion führen und welche weiteren Faktoren, wie z.B. eine akute und chronische Herzinsuffizienz, den SP-B-Plasmaspiegel beeinflussen. Möglicherweise würden sich hierbei unterschiedliche cut-off-Werte bei akuter und chronischer Dyspnoe sowie bei schwerer akuter kardio-pulmonaler Schädigung als sinnvoll erweisen. Die Ergebnisse bisheriger Studien (DePasquale et al. 2004, Doyle et al. 1997, Pascual-Figal et al. 2009) beschreiben interessanterweise für das SP-B eine wichtige diagnostische Bedeutung bei Patienten mit einer pulmonalen und chronisch kardiopulmonalen Ursache der Dyspnoe.

In unserer Studie zeigten sich ähnliche Plasmaspiegelveränderungen des SP-D wie beim NT-proBNP bei einer kardialen Genese der akuten Dyspnoe. In bisherigen Untersuchungen wird das SP-D in erster Linie als beeinflussender Faktor bei der Immunabwehr der Lunge und im Bezug auf die Homöostase der Surfactant Proteine beschrieben (Ikegami et al. 2001, Crouch 2000, Jounblat et al. 2005). Die in unserer Studie dargestellten erhöhten Plasmaspiegel des SP-D bei einer kardialen Ursache der akuten Luftnot weisen auf eine weitere Beeinflussung des SP-D-Plasmaspiegels durch Änderungen der kardiopulmonalen Hämodynamik hin. Es benötigt jedoch weitere Untersuchungen, um diese Wertigkeit des SP-D zu präzisieren und die Frage nach Serumspiegelveränderungen bei akuten und chronischen Veränderungen der Luftnot zu objektivieren. Dabei ist auch eine Beeinflussung des SP-D bei akuten pulmonalen bzw. kardiopulmonalen strukturellen Veränderungen anzunehmen, da in einigen bisherigen Studien SP-D-Plasmaspiegelerhöhungen als ein Marker des ARDS und der zugrunde liegenden Lungengewebsschädigung beschrieben worden sind. Dabei wurde gezeigt, dass ein erhöhter SP-D-Plasmaspiegel mit einem schlechteren Outcome der Patienten mit ARDS einhergeht (Eisner et al. 2003, Greene et al. 1999).

Die Bestimmung der SP-D Plasmaspiegel konnte in unserer Studie bei der kardialen Ursache der akuten Luftnot die Sensitivität und Spezifität in der Diagnostik der akuten Dyspnoe im Vergleich zu dem NT-proBNP Plasmaspiegel leicht, aber nicht signifikant, erhöhen. 
Es konnte in unserer Studie nicht gezeigt werden, dass eine akute Dyspnoe bei einer primär pulmonalen Ursache mit erhöhten Serumspiegeln des SP-B oder SP-D einhergeht.

Unter Berücksichtigung unserer initialen Hypothese, dass die Bestimmung der SP-D oder SP-B-Plasmaspiegel die Diagnostik einer akuten Dyspnoe weiter verbessern kann, konnte gezeigt werden, dass SP-D ähnliche Plasmaspiegelveränderungen bei Patienten mit akuter Dyspnoe im Vergleich mit dem NT-proBNP aufweist. Es fand sich in unserer Studie jedoch kein signifikanter Unterschied der SP-B Plasmaspiegel zwischen den einzelnen Subgruppen der Ursache einer akuten Dypnoe. Die Diagnosegenauigkeit zur Differenzierung der Ätiologie einer akuten Dyspnoe konnte durch die Bestimmung der Surfactant Proteine nicht signifikant verbessert werden.

Zusammen mit genaueren Nachweisverfahren der Surfactant Proteine sowie durch die ähnlichen Plasmaspiegelveränderungen des SP-D, in Bezug auf den NT-proBNP Plasmaspiegel, kann in Zukunft den Surfactant Proteinen eine weitere Bedeutung im Rahmen der Diagnostik akuter oder chronischer kardiopulmonaler Erkrankungen zukommen.

Folgende Einschränkungen sollten bei der vorliegenden Studie berücksichtigt werden: Erstens wurden die Blutproben initial bei $-80^{\circ} \mathrm{C}$ konserviert. Während der Analysen können wir die Möglichkeit eines Proteinabbaus nicht gänzlich ausschließen, wobei die Proben dabei nur einmalig aufgetaut worden sind und sich dabei die NTproBNPPlasmaspiegel in der frischen und in der aufgetauten Probe als identisch erwiesen.

Zweitens ist die Aufnahme von Studienteilnehmern in diese Studie einer gewissen Selektion unterlegen. Die Patienten wurden ausschließlich über die Notaufnahme der Universitätsklinik Göttingen aufgenommen. In den nicht-universitären, peripheren Krankenhäusern präsentiert sich das Krankheitsbild einer akuten Dyspnoe möglicherweise heterogener. Dabei repräsentiert die Zusammensetzung unserer Studienpopulation die Zusammensetzung der in unserer Notaufnahme zu versorgenden Patienten.

Es ist es nicht Ziel dieser Studie gewesen, die Mechanismen der Aktivierung natriuretischer Peptide und der Surfactant Proteine zu klären. In früheren Untersuchungen 
wird die Vermutung aufgestellt, dass in Fällen einer sehr ausgeprägten akuten Herzinsuffizienz die natriuretischen Peptide sowie die Surfactant Proteine weiteren Wechselwirkungen ausgesetzt sein könnten (Tsutamoto et al.1997, De Pasquale et al.2003, Pascual-Figal et al. 2009). Dieses bedarf weiterer Untersuchungen.

Viertens wurde der Effekt therapeutischer Maßnahmen auf die Plasmakonzentrationen des NT-proBNP nicht in dieser Studie berücksichtigt. Dabei kann ein Effekt der vielfältigen Therapieoptionen auf die Plasmakonzentrationen nicht ausgeschlossen werden. In einer Studie von Troughton et al. (2000) bei an der Plasmakonzentration des NT-proBNP orientierten Therapie einer Herzinsuffizienz und einer im Vergleich zur am klinischen Verlauf orientierten Therapie wird über eine deutlich verbesserte Prognose der Herzinsuffizienz berichtet. In einer Arbeit von Davis et al. (2006) zeigte sich ein Einfluss einer medikamentösen Therapie mit Metoprolol auf den NT-proBNP Plasmaspiegel. Es ist jedoch derzeit noch unklar, ob alle Patienten mit einer akut dekompensierten Herzinsuffizienz auf eine erfolgreiche Therapie mit dem Abfall der Plasmakonzentrationen des NT-proBNP reagieren. Der Zeitpunkt einer pharmakologischen Intervention könnte von Wichtigkeit für die gemessenen NT-proBNP Plasmaspiegel sein. Festzuhalten ist jedoch, dass respektive der pharmakokinetischen Eigenschaften des NT-proBNP weniger ein Einfluss auf die frühzeitig gemessenen Plasmaspiegel zu erwarten ist, als auf die Plasmakonzentrationen, die Tage und sogar Wochen nach einem Ereignis bestimmt werden.

Weiter ist die genaue Beeinflussung der akuten und chronischen Herzinsuffizienz sowie der akuten und chronischen Lungenerkrankungen auf die Plasmaspiegel der Surfactant Proteine derzeit unklar.

Auch wurde der Einfluss der Nierenfunktion sowie der linksventrikulären Pumpfunktion auf die Serumkonzentration der natriuretischen Peptide nicht in dieser Studie berücksichtigt. In einigen Studien konnte ein Zusammenhang zwischen der Nierenfunktion sowie der linksventrikulären Pumpfunktion und den NT-proBNP Plasmaspiegeln beschrieben werden (Luchner et al. 2000, Luchner et al. 2002). Die Beeinflussung der Surfactant-Protein Plasmaspiegel durch eine eingeschränkte Nierenfunktion oder eine 
eingeschränkte linksventrikuläre Pumpfunktion bedürfen noch weiterer Untersuchungen.

In dieser Studie handelt es sich um eine „Single Center“- Studie. Die Reproduzierbarkeit in anderen Zentren oder durch eine multizentrische Studie würden für ihre Gültigkeit sprechen. Zur differentialdiagnostischen Aussagekraft des NT-proBNP bei der akuten Dyspnoe wurden bereits die Daten einiger „Single Center“-Studien in anderen multizentrischen Studien bestätigt (Lainchbury et al. 2003, Davis et al. 1994, Januzzi et al. 2005, Murray et al. 2006). 


\section{Zusammenfassung}

In Übereinstimmung mit bisherigen Studien (Lainchbury et al. 2003, Davis et al. 1994, Januzzi et al. 2005, McCullough et al. 2002) konnte gezeigt werden, dass die Bestimmung von NT-proBNP eine hohe Sensitivität und Spezifität für die Differentialdiagnose der akuten Dyspnoe besitzt. In unserer Studie konnte die Bestimmung der Surfactant Protein-B- und -D-Plasmaspiegel die Differentialdiagnostik der akuten Dyspnoe nicht signifikant verbessern. Interessanterweise zeigte sich ein signifikant erhöhter SPD-Serumspiegel bei den Patientengruppen mit einer kardialen Genese der akuten Dyspnoe. Die physiologische- bzw. pathophysiologische Bedeutung des SP-D bei einer kardialen Genese der akuten Dyspnoe bedarf weiterer Untersuchungen.

Möglicherweise kommt dem Surfactant Proteinen-D, ähnlich wie dem NT-proBNP, eine weitere Bedeutung im Rahmen der Diagnostik akuter oder chronischer kardiopulmonaler Erkrankungen zu.

Im Vergleich hierzu kommt nach unseren Ergebnissen dem SP-B für die Differenzialdiagnostik bei akuter Dyspnoe keine Bedeutung zu. 


\section{Literaturverzeichnis:}

American Thoracic Society (1999): Dyspnea: mechanisms, assessment, and management: a consensus statement. Am J Respir Crit Care Med 159:321340

Biering S, Ehler D, Knoll M, Waggoner A: ASE Minimum Standards for the cardiac sonographer: A position paper. A Report from the Council of Cardiac Sonography of the American Society of Echocardiography. ASE Raleigh 2005

Cabanes L, Richaud - Thiriez B, Fulla Y, Heloire F, Vuillemard C, Weber S, Dusser D (2001): Brain Natriuretic Peptide Blood Levels in the Differential Diagnosis of Dyspnea. Chest 120 (6): 2047- 2050

Classen M, Diehl V, Koch K-M, Kochsiek K, Pongratz P, Scriba M :

Differentialdiagnose Innere Medizin.. Urban \& Schwarzenberg-Verlag, Stuttgart $1998 ; 21-39$

Crouch E (2000): Surfactant protein-D and pulmonary host defense. Respir Res 1:93-108

Davis M, Espiner E, Richards G, Billings J, Town I, Neill A, Drennan C, Richards M, Turner J, Yandle T (1994): Plasma brain natriuretic peptide in assessement of acute dyspnoea. Lancet 343: 440-44

Davis M, Richards A, Nicholls M, Yandle T, Frampton C, Troughton R, (2006): Introduction of metoprolol increases plasma B-type cardiac natriuretic peptides in mild, stable heart failure. Circulation 113 (7):977-85

De Pasquale C, Bersten A, Doyle I, Aylward P, Arnolda L (2003): Infarct-induced chronic heart failure increases bidirectional protein movement across the alveolocapillary barrier. Am J Physiol Heart Circ Physiol 284: H2136-H2145,

De Pasquale C, Arnolda L, Doyle I, Aylward P, Chew D, Bersten A (2004):

Plasma Surfactant Protein-B, A Novel Biomarker in Chronic Heart Failure. Circulation 110:1091-1096

Doyle I, Nicholas T, Bersten A (1995): Serum surfactant protein-A (SP-A) levels in patients with acute cardiogenic pulmonary edema and adult respiratory distress syndrome. Am. J. Respir. Crit 152:307-17 
Doyle I, Bersten A, Nicholas T (1997): Surfactant Proteins-A and -B Are Elevated in Plasma of Patients with Acute Respiratory Failure. Am J Respir Crit Care Med 156:1217-1229

Eisner M, Parsons P, Matthay M, Ware L, Greene K (2003): Plasma surfactant protein levels and clinical outcomes in patients with acute lung injury. Tho$\operatorname{rax} \underline{58}: 983-988$

Ellis R, Levin E, Gardner D, Samson W (1998): Natriuretic Peptides. N Engl J Med 339, 5, 321-328

Erdmann E: Herzinsuffizienz. Ursachen, Pathophysiologie und Therapie. 3. Auflage; Wissenschaftliche Verlagsgesellschaft, Stuttgart 2003

Erpenbeck V , Ziegert M, Cavalet-Blanco D, Martin C, Baelder R, Glaab T, Braun A., Steinhilber W, Luettig B, Uhlig S , Hoymann H G, Krug N, Hohlfeld J (2006): Surfactant protein D inhibits early airway response in Aspergillus fumigatus-sensitized mice. Clin Exp Allergy 36, 930-940

Greene K, Wright J, Steinberg K, Ruzinski J, Caldwell E, Wong W, Hull W, Whitsett J, Akino T, Kuroki Y, Nagae H, Hudson L, Martin T (1999): Serial Changes in Surfactant-associated Proteins in Lung and Serum before and after Onset of ARDS. Am J Respir Crit Care Med 160:1843-1850

Hawgood S (2004): Surfactant Protein B: Structure and Function. Biol Neonate $\underline{85}: 285-289$

Hoppe U, Böhm M, Dietz R, Hanrath P, Kroemr H,. Osterspey A, Schmaltz A, Erdmann E (2005): Leitlinien zur Therapieder chronischen Herzinsuffizienz. Z Kardiol 94:488-509

Ikegami M, Hull W, Yoshida M, Wert S, Whitsett J (2001): SP-D and GM-CSF regulate surfactant homeostasis via distinct mechanisms. Am J Physiol Cell Mol Physiol 281: L697-L703

Januzzi J, Camargo C, Anwaruddin S, Baggish A, Chen A, Krauser D, Tung R, Cameron R, Nagurney T, Chae C, Lloyd-Jones D, Brown D, ForanMelanson S, Sluss P, Lee-Lewandrowski E, ewandrowski K (2005): The Nterminal Pro-BNP Investigation of Dyspnea in the Emergency department (PRIDE) study. Am J Cardiol 95:948 -54. 
Januzzi J, van Kimmenade R, Lainchbury J, Bayes-Genis A, Ordonez- Llanos J, Santalo-Bel M, Pinto YM, Richards M (2006): NT-proBNP testing for diagnosis and short-term prognosis in acute destabilized heart failure: an international pooled analysis of 1256 patients: the International Collaborative of NT-proBNP Study. Eur Heart J 27:330 -337.

Jounblat R, Clark H, Eggleton P, Hawgood S, Andrew P, Kadioglu A (2005): The role of surfactant protein $\mathrm{D}$ in the colonisation of the respiratory tract and onset of bacteriaemia during pneumococcal pneumonia. Respir Res 28; $6: 126$

Kishore U, Greenhough T., Waters P, Shrive A., Ghai R, Kamran M, Bernal A, Reid K, Madan T, Chakraborty T (2006): Surfactant proteind SP-A and SPD: structure, function and receptors. Mol Immunol $\underline{43}$ 1293-1315

Lainchbury J, Campbell E, Frampton C, Yandle T, Nicholls M, Richards A (2003): Brain natriuretic peptide and n-terminal brain natriuretic peptide in the diagnosis of heart failure in patients with acute shortness of breath. J Am Coll Cardiol 42: 728-35.

Little, Brown \& Co: The Criteria Committee of the New York Heart Association In: Nomenclature and Criteria for Diagnosis of Diseases of the Heart and Great Vessels. 9th ed. American Heart Association, Boston, Mass; 1994: 253-256

Luchner A, Burnett J, Jougasaki M, Hense H, Heid I, Muders F, Riegger G, Schunkert H (2000): Evaluation of brain natriuretic peptide as marker of left ventricular dysfunction and hypertrophy in the population. J Hypertens $\underline{18}$ : $1121-1128$.

Luchner A, Hengstenberg C, Loewel H, Trawinski J, Baumann M, Riegger G, Schunkert H, Holmer S (2002): N-terminal pro-brain natriuretic peptide after myocardial infarction: a marker of cardiorenal function. Hypertension 39: 99-104.

Luchner A, Holmer S, Schunkert H, Riegger G (2003): Bedeutung der Herzinsuffizienzmarker BNP und NT-proBNP für die Klinik. Dtsch Arztebl 100: $3314-3321$ [Heft 50] 
Mair J, Hammerer-Lercher A, Puschendorf B (2001): The Impact of Cardiac

Natriuretic Peptide Determiniation on the Diagnosis and Management of Heart Failure. Clin Chem Lab Med 39 (7): 571-588

Maisel A, Krishnaswamy P, Nowak R, McCord J, Hollander J, Duc P, Omland T, Storrow A, Abraham W, Wu A (2002): Rapid measurement of B-type natriuretic peptide in the emergency diagnosis of heart failure. $\mathrm{N}$ Engl J Med 347:161-167.

Mark D, Felker G (2004): B-type natriuretic peptide-a biomarker for all seasons. N Engl J Med 350:718 - 720.

McCullough P A, Nowak R M, McCord J, Hollander J, Herrmann H, Steg P, Duc P, Westheim A, Omland T, Knudsen C, Storrow A, Abraham W, Lamba S, Wu A, Perez A, Clopton P, Krishnaswamy P, Kazanegra R, Maisel A. (2002): B-type natriuretic peptide and clinical judgment in emergency diagnosis of heart failure: analysis from breathing not properly (BNP) Multinational Study. Circulation; 106:416-422

McKee P, Castelli W, McNamara P, Kannel W (1971): The Natural History of Congestive Heart Failure: The Framingham Study. N Engl J Med 285: 14411446

Moe G, Howlett J, Januzzi J, Zowall H (2007): N-terminal pro-B-type natriuretic peptide testing improves the management of patients with suspected acute heart failure. Primary Results of the Canadian Prospective Randomized Multicenter IMPROVE-CHF Study. Circulation 115:3103-3110

Müller C, Kuster G, Büttner H, Buser P (2003): B-Typ-natriuretisches Peptid. Herz 28; 5: 374-378

Müller C, Scholer A, Laule-Kilian K, Martina B, Schindler C, Buser P, Pfister M, Perruchoud A (2004): Use of B-Type Natriuretic Peptide in the Evaluation and Management of Acute Dyspnoea. N Engl J Med 350: 647-654

Murray H, Cload B, Collier C, Sivilotti M (2006): Potential impact of N-terminal pro-BNP testing on the emergency departement evaluation of acute dyspnea. Can J Emerg Med $\underline{8}$ (4): 251-8 
o.Verf.(o.J.):Produktinformation Elecsys ${ }^{\circledR}$ proBNP 2004-

Elektrochemilumineszenz- Immunoassay (ECLIA) zur vollautomatischen, standardisierten Bestimmung des aminoterminalen Typ B natriuretischen Peptids (NT-proBNP) in Serum oder Plasma. Elecsys ${ }^{\circledR}$ systeme 1010/2010/Modular Analytics, Roche Diagnostics GmbH, D-68298 Mannheim (2002-11-2176882001 05 04);

Pascual-Figal D, Sanchez-Mas J, de la Morena G, Casas T, Garrido I, Ruiperez

J, Valdes M (2009): Pulmonary Surfactant Protein B in the Peripheral Circulation and Functional Impairment in Patients with chronic heart failure. Rev Esp Cardiol 62 (2): 136-42

Pastva A, Wright J, Williams K (2007): Immunomodulatory Roles of

Surfactant Proteins A and D, Implications in Lung Disease. Proc Am Thorac Soc 4: 252-257,

Ray P, Arthaud M, Lefort Y, Birolleau S, Beigelman C, Riou B (2004): Usefulness of B-type natriuretic peptide in elderly patients with acute dyspnea. Intensive Care Med 30: 2230-2236

Redfield M, Rodeheffer R, Jacobsen S, Mahoney D, Bailey K, Burnett J (2002):

Plasma brain natriuretic peptide concentration: impact of age and gender. $\mathrm{J}$ Am Coll Cardiol 40: 976-982

Richards A, Nicholls M, Yandle T (1998): Plasma N-terminal pro-brain natriuretic peptide and adrenomedullin: new neurohormonal predictors of left ventricular function and prognosis after myocardial infarction. Circulation 97: 1921-29.

Shepherd V.(2002): Pulmonary surfactant protein D: a novel link between innate and adaptive immunity. Am J Physiol Lung Cell Mol Physiol 282: L516-L517

Siegenthaler W: Differentialdiagnose Innerer Krankheiten, Thieme Verlag, Stuttgart 2000, S. 448- 468

Troughton R, Frampton C, Yandle T, Espiner E, Nicholls M, Richards A (2000): Treatment of heart failure guided by plasma aminoterminal brain natriuretic peptide (N-BNP) concentration. Lancet 355: 1126-30 
Tsutamoto T, Wada A, Maeda K, Hisanaga T, Maeda Y, Fukai D, Ohnishi M, Sugi moto Y, Kinoshita M (1997): Attenuation of compensation of endogenous cardiac natriuretic peptide system in chronic heart failure: prognostic role of plasma brain natriuretic peptide concentration in patients with chronic symptomatic left ventricular dysfunction. Circulation $\underline{96}$ (2): 509-516

Whittset J, Weaver T (2002): Hydrophobic Surfactant Proteins In Lung Function and Disease. N Engl J Med 347: 2141-2147 


\section{Danksagung}

Ich danke meinem Betreuer Dr. Claus Lüers. Neben zahlreichen Anregungen hat er mich stets bei auftretenden Problemstellungen unterstützt.

Ebenso danke ich Herrn Prof. Dr. med. Burkhard Pieske für die freundliche Überlassung des Themas, die konstruktive Kritik und die gewährte Unterstützung.

Mein besonderer Dank gilt meinen Eltern sowie meiner Frau Inga für die ergänzenden Korrekturen und für die damit verbundene Unterstützung zum erfolgreichen Abschluss der Dissertation. 


\section{Lebenslauf}

Am 18. Mai 1977 wurde ich, Jens Schaumberg, als zweites Kind der Eheleute Gerhard und Rosemarie Schaumberg, geb. Klug, in Halberstadt geboren.

Mein Bruder Torsten Schaumberg, Fachanwalt für Arbeitsrecht, wurde am 19. Februar 1971 geboren.

Seit dem 11.09.09 bin ich mit meiner Frau Inga Schaumberg, geb. Birnbaum, verheiratet. Unser Sohn Anton C. Schaumberg wurde am 30. Juni 2008 in Hamburg geboren.

Von 1983 bis 1989 besuchte ich die Käthe-Kollwitz Oberschule in Halberstadt. Im Jahr 1989 wechselte ich auf die Ernst-Schmidt- Oberschule in Halberstadt. Im Jahr 1991 wechselte ich auf das Gymnasium Martineum in Halberstadt, wo ich 1995 die allgemeine Hochschulreife erreichte.

Im Zeitraum von Oktober 1995 bis September 1996 leistete ich meinen Grundwehrdienst mit Grundausbildung im Luftwaffenausbildungsregiment 14 in Heide und den weiteren Wehrdienst in der Radarführungskompanie 131 in Eckernförde.

In der Zeit bis zum Beginn des Studiums arbeitete ich in verschiedenen handwerklichen Berufen wie Hoch-, Tief-, Fernmelde- und Fensterbau. Vom Sommersemester 1998/ 1999 bis einschließlich zum Sommersemester 2004/ 2005 studierte ich an der Georg-August-Universität Göttingen Humanmedizin. Im Sommer 2002 begann ich nach erfolgreich abgelegtem Physikum und 1. Staatsexamen meine Dissertationsarbeit im Zentrum Innere Medizin, Abteilung Kardiologie und Pneumologie (Prof. Dr. med. G. Hasenfuß), Herzzentrum, bei Prof. Dr. med. B. Pieske. Mein 2. und 3. Staatsexamen legte ich in den Jahren 2004 und 2005 ab.

Meine Famulaturen absolvierte ich unter anderem in der Anästhesiologie, der Inneren Medizin sowie einer kardiologischen Gemeinschaftspraxis. Die Tertiale meines Praktischen Jahres absolvierte ich in Bremen. Das Tertial Innere Medizin sowie Chirurgie im Klinikum Bremen Mitte und mein Wahltertial Neurologie im Klinikum BremenOst. 
Vom 01.06.2006 bis zum 31.06.2008 arbeitete ich als Assistenzarzt in der Neurologie des Klinikums Bremen-Mitte. Seit dem 01.08.2008 bin ich als Assistenzarzt in der Asklepios Klinik Hamburg Altona tätig. 